\title{
DETERMINANTS OF GOVERNMENT BOND SPREADS IN NEW EU COUNTRIES
}

by loana Alexopoulou, Irina Bunda and Annalisa Ferrando 


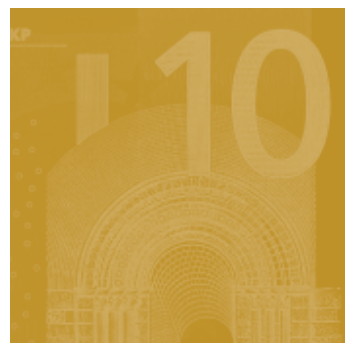

\title{
WORKING PAPER SERIES
}

NO 1093 / SEPTEMBER 2009

\section{DETERMINANTS OF GOVERNMENT BOND SPREADS IN NEW EU COUNTRIES ${ }^{\prime}$}

\author{
by Ioana Alexopoulou, ${ }^{2}$ Irina Bunda ${ }^{2}$
}

and Annalisa Ferrando ${ }^{2}$

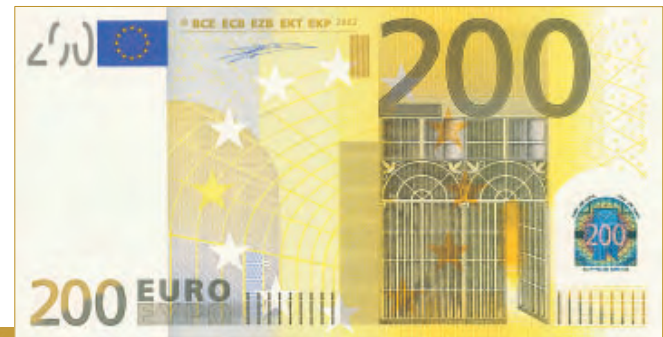

In 2009 all ECB electronic library at http://ssrn.com/abstract_id $=1474275$. 
(C) European Central Bank, 2009

Address

Kaiserstrasse 29

60311 Frankfurt am Main, Germany

Postal address

Postfach 160319

60066 Frankfurt am Main, Germany

Telephone

+496913440

Website

http://www.ecb.europa.eu

\section{Fax}

+496913446000

All rights reserved.

Any reproduction publication and reprint in the form of a different publication, whether printed or produced electronically, in whole or in part, is permitted only with the explicit written authorisation of the ECB or the author(s).

The views expressed in this paper do not necessarily reflect those of the European Central Bank

The statement of purpose for the ECB Working Paper Series is available from the ECB website, http://www.ecb.europa. eu/pub/scientific/wps/date/html/index. en.html

ISSN 1725-2806 (online) 


\section{CONTENTS}

Abstract

Non-technical summary

1 Introduction

2 Literature review and objective of the paper

7

3 Methodological issues and data description

3.1 The model

3.2 Choice of variables

4 Empirical results

4.1 Long-run determinants and short-run dynamics

4.2 Do investors differentiate across the new EU countries?

4.3 Dynamics of fundamental-driven spreads

4.4 Robustness checks

5 Policy implications and conclusions

References

Appendices

European Central Bank Working Paper Series 


\begin{abstract}
Based on a rich database of government bond spreads and macroeconomic indicators over the period 2001-2008, we propose an empirical assessment of the role of fundamentals in driving long-term sovereign bond spreads of the new EU countries (Bulgaria, Czech Republic, Latvia, Lithuania, Hungary, Poland, Romania and Slovakia). The results of a dynamic panel error correction model that accounts for both common long-run determinants and cross-country heterogeneities in sovereign bond spreads tend to suggest that fundamentals still matter for market's assessment of a country creditworthiness. Countries' levels of external debt, fiscal and current account balances, exchange and inflation rates, their degree of trade openness as well as short-term interest rate spreads play an important role in the new EU countries' access to long-term finance. We furthermore challenge the pooled mean approach in order to check whether other factors may become relevant in the long-run for two subgroups of countries according to the developments in their current account balances. Fiscal fundamentals seem to matter most for one group of countries, those characterised by widening external imbalances and historically high levels of spreads. In a context of heightened risk aversion and potential for spill over effects, this group of countries are more exposed to domestic sources of vulnerability as well as to swings in market perceptions of sovereign risks.
\end{abstract}

Keywords: long-term government bond spreads, new EU countries, pooled mean group estimation.

JEL Classification: G12, H60, E62 


\section{Non-technical summary}

Among the Maastricht convergence criteria used for assessing the countries, which are in the process of entering into the euro-zone, the long-term interest rate is a measure of the durability and sustainability of a country's convergence process, or, put it differently, a reflection of the financial market assessment of the economic fundamentals' sustainability, particularly with a view to the stability of the fiscal balance and risk premia. In the regular analysis carried out by the Eurosystem, the assessment is based on the convergence of ten-year government bond yields to the euro area average.

Against this background, The aim of this paper is to investigate the empirical determinants of government bond spreads in new EU countries (Bulgaria, Czech Republic, Latvia, Lithuania, Hungary, Poland, Romania and Slovakia; for Estonia no comparable long-term government bond interest rate is available), taken together or by clusters formed according to their relative degree of external vulnerability. The present analysis, performed on the difference between the long-term government bonds yields used for convergence purposes relative to the average of the equivalent euro area benchmark, has implications for the convergence process of each country as well as their ability to access external financing.

The group as a whole shows considerable amount of heterogeneity in the short-run, persistence and an adjustment trend to equilibrium values over medium to long run, as part of the convergence process. In order to account for these countries' features that distinguish themselves from other emerging economies, we adopt a dynamic panel approach based on the pooled mean group (PMG) technique first proposed by Pesaran, Shin and Smith (1999). This is basically an error correction model allowing for both long-run homogeneity and short-run differences in coefficients and error variances across countries. The use of spreads against a euro area average together with this econometric approach, are novel in the literature on new EU countries.

Among the explanatory variables, we aim at quantifying the role of country-specific fundamentals, a common factor as well as of financial market integration in explaining government bond spreads in the new EU countries. The best empirical specification includes, among fundamentals, external debt, interest payments on government debt, trade openness, current account and fiscal balances, exchange rate, per capita income, inflation rate and short-term interest rates differentials relative to the euro area. We control for only one euro area common factor, namely the euro area stock market volatility.

We find that external debt, fiscal balance, inflation rate, trade openness, exchange rates as well as the short-term interest rate spreads are the main long-run determinants of government spreads in the new EU countries during the period January 2001 to December 2008.

Furthermore, we check whether these government bonds spreads display different long-run equilibrium paths and pooling them all together in only one group in the long-run may make us lose information on their determinants. In this respect, our analysis suggests that a good separation of countries is based on a number of criteria among which the state of their current account balance, external debt and inflation rates have an important role to play. We identify a sub-group of countries characterised by increasing spreads, especially over the recent period: Bulgaria, Latvia, Hungary and Romania, for which the main drivers of spreads include fiscal variables (the interest payments on government debt ratio), external variables (external debt, exchange rates, trade openness) as well as well as the short-term interest rate differential relative to the euro area three-month month EURIBOR rate. Spreads of countries in this group are also negatively related to the common factor (euro area equity volatility).

The other sub-group of countries -Czech Republic, Lithuania, Poland and Slovakia- characterised by low and decreasing spreads for prolonged periods in the sample, are mainly driven by the current account balance, inflation rates and, as in the case of the high spread sub-group, by short-term interest rate differentials relative to the euro area and euro area equity volatility. However, the relationship with the common factor (euro area equity volatility) is positive, suggesting a different reaction, from the initial sample, to external shocks. The fiscal balance situation seems to matter less, even if countries in this sub-group display very heterogeneous fiscal positions.

Based on the estimated coefficients, we then derive the dynamics of fundamental-driven spreads, with implications for the assessment of the convergence progress in the new EU countries as well as of potentially risks ahead. We show that for some countries (Bulgaria, Latvia, Lithuania, Hungary and Romania) the fundamental-based spreads are on a rising path since the beginning of the financial crisis and the upward trend is likely to continue in a context of heightened risk aversion and unfavourable economic activity environment. 
As regards the recent period of market turmoil starting in summer 2007, our estimated results suggested that the rise in spreads in countries like Hungary and Romania is driven by a mix of deteriorating fundamentals and increased dependence upon external conditions. In Bulgaria, Latvia and Lithuania, fundamentals have become prevalent in 2008 and their recent abrupt deterioration has immediately translated into higher risk premia required by investors to hold government debt securities. For other countries in the sample -the Czech Republic and Slovakia- we noticed that fundamental-driven spreads are, at times, slightly higher than actual ones. In the case of Poland, our estimates do not show changes in the pattern of government bond spreads with fundamentals mostly explaining actual spreads. As an application of our model, we present a simulation exercise based on the PMG specification that quantifies the impact of any changes to fundamentals may have upon financing conditions in the new EU countries as captured by government bond spreads. 


\section{Introduction}

Assessing new EU countries overall financing conditions plays a pivotal role in the process of nominal convergence as it provides evidence on their credit risk quality which could entail implications on their borrowing needs and their ability to maintain a sustained path towards economic and financial integration with the euro area.

Even if in the process, sometimes the more muted market reaction toward the new EU countries as a group has contrasted with growing macroeconomic imbalances and short-run discrepancies, it is important to study what accounts for the market reaction at the country-level while not losing sight of the broad picture. What is the relative part of fundamentals, euro area factors and market behaviour in explaining the borrowing costs new EU countries are facing in the capital markets? Have these factors evolved over time? Does their importance tend to shift in times of heightened market volatility? Such an inquiry into investors' perceptions of countries' creditworthiness becomes all the most important at the current juncture, when after years of vigorous capital inflows into the region, risks are looming that they can suddenly come to a halt. Not only sovereign credit conditions may be influenced by the quality of domestic macroeconomic policies but these also leave countries asymmetrically exposed to spillover effects from external shocks.

Previous studies, mainly on government bond spreads for most of the current euro area members, have found that not only macroeconomic fundamentals are relevant in determining sovereign spreads but also external factors, either easily proxied for, like global liquidity, for instance, or latent ones, related for instance to policy credibility considerations. However, empirical literature on the new EU countries spreads as a group is rather scarce.

We aim at filling the gap in the literature by applying a methodology on government bond yields against a euro area average and propose an analysis of bond spreads in the new EU countries as distinct from other emerging economies.

To this end, we develop an empirical model of sovereign spreads that account for the long-run determinants of the longterm yield spreads together with their short-run dynamic behaviour. The adopted approach is basically a dynamic error correction model, based on the pooled mean group technique of Pesaran, Shin and Smith (1999) with heterogeneous short-run and homogenous long-run cross-section coefficients. The estimated model will then enable us to derive a fundamental-based measure of sovereign spreads, where the divergence of actual from estimated spreads could reflect higher investors risk appetite, spillover effects or market tiering. Once we set the long-run path of the new EU countries spreads, we assess the likely impact that a shock to fundamentals may have on the actual spreads.

The rest of the paper is organised as follows. Section 2 reviews the related empirical literature and formulates the objective of the paper. Section 3 is describing the theoretical model used and provides the dataset description. Our main empirical results, for the long and the short-run, together with a decomposition of the spreads, clustering and robustness checks are presented in Section 4. Finally, in Section 5 we summarise our main findings and discuss the implications of the overall results for the new EU countries.

\section{Literature review and objective of the paper}

The empirical analysis of government bond yield spreads goes back to Edwards (1984) who first related sovereign spreads to the market perception of countries' risk of default on sovereign debt. As such, sovereign spreads can be explained by a set of domestic as well as international, macroeconomic, fiscal and financial variables that enter an investors' assessment of a country's creditworthiness.

For the purposes of our investigation, we briefly present in what follows two strands of the literature related to empirical models of government bond yields spreads. The first relates to the analysis of euro area government bond markets, while the second refers to emerging markets, with some focus to the new EU countries.

In reference to the euro area government bond markets, most studies have focused on disentangling the role of the two main components of spreads i.e. the credit default and the liquidity risks in explaining movements in yield differentials. Whether the role of macroeconomic and fiscal fundamentals is important, it will appear in the credit risk component of spreads. By contrast, the role of international financial conditions will mainly affect their liquidity component, mirroring investors' risk preferences 
Combining monthly and daily data from 1995 to 2002 into a SURE dynamic model, Codogno, Missale and Favero (2003) decompose the observed movements in yield differentials of euro area member countries, as captured by the relative asset swap spreads, into fundamental and liquidity-driven components, and found that global factors, characterising mainly the US market, are prevalent in explaining yield differences in almost all the euro area countries. Moreover, they conclude that default risk measures help in explaining a substantial part of changes in spreads for some of the euro area countries, while, for others, international factors have a role to play, but this, independently of their underlying fiscal conditions. Different liquidity conditions or unobserved fundamentals such as reputation/credibility issues, as well as greater uncertainty over future budget surpluses are all plausible explanations of the apparent discrepancy between countries fundamentals and market assessment of their sovereign risk.

Schuknecht, von Hagen and Wolswijk (2008) analyse risk premia paid by the central and sub-central government sectors in the euro area and Canadian provinces for borrowing in the bond market from 1991 to 2005. Based on a standard portfolio theory model, government bond spreads depend positively on the domestic bond yield, negatively on the yield on an alternative asset, government's default probability, liquidity premium and investors' risk aversion. The specified model is then tested on different proxies of spreads determinants, among which, several indicators of fiscal performance account for the government's probability of default. Their results show that bond spreads depend significantly on a range of indicators of fiscal performance, although the nature and magnitude of sovereign risk premia has changed concomitant to the adoption of the euro. Consistent with Pagano and von Thadden (2004) and Favero, Pagano and von Thadden (2005), liquidity premia also have a role to play in driving spreads in the euro area, especially before the introduction of the euro.

More recently, Manganelli and Wolswijk (2009) decompose the spreads of euro area government bonds during the period 1999- 2008 into a credit risk and a liquidity risk premium. The credit risk premium measures the financial compensation investors demand to cover the risk that a government defaults while the liquidity risk premium measures the extra interest rate an investor requires to be compensated for bearing the risk of having to liquidate the security at a lower price with respect to the benchmark. From a policy perspective this decomposition is important: a large default risk premium is associated with market discipline related to the sustainability of public finances, while a large liquidity premium may indicate incomplete bond market integration, pointing to the need for further harmonization of technical standards and bond issuance policies. Moreover, they find the existence of a positive relation between short-term interest rates as set by the Eurosystem and euro area government bonds spreads and in particular that the sensitivity of government bond spreads to short-term interest rates increases as the credit quality of the underlying bond deteriorates. ${ }^{1}$ Finally, the study by Geyer, Kossmeier and Pichler (2004) for the euro area reaches a different conclusion as regards the relative role of fundamentals and common factors in driving yield differentials. Based on the assumption that their dynamics may be driven by common latent factors, they propose a state space approach for modelling spreads and use weekly frequency data for a selected group of euro area member states. The authors find strong evidence that government bond spreads are related to the evolution of alternative euro area asset markets, as a sign of increased market integration, and much less so, to macroeconomic or liquidity variables.

Turning to bond valuations of new EU countries and their determinants, many studies have analysed them as part of the broader emerging market economies (EMEs) group based on EMBI+ and its successor, EMBI Global Indexes. ${ }^{2}$ Among them, Ferrucci (2003) uses an unbalanced, ragged-edge panel of monthly observations covering around 40 emerging market countries during the period 1992-2002. Spreads determinants are explained using a dynamic error correction panel estimation based on the pooled mean group (PMG) technique of Pesaran, Shin and Smith (1999). Using PMG as an intermediate solution between fixed effects and individual countries estimates can help to explain the long-run determinants of emerging markets bond spreads along with some short-run dynamics behaviour. The estimation results of the equilibrium relationship show that country's fundamentals and external liquidity conditions are important determinants of market spreads for the EMEs. Nevertheless, the author points out that the

\footnotetext{
${ }^{1}$ Looking at credit and liquidity risks from a different angle - using a flow of funds analysis of intraday bond quotes and transactions over a two years' period (2003-2004)- Beber et al.(2008) show that cross-country heterogeneities in credit quality account for the bulk of sovereign spreads. Liquidity plays a nontrivial role, especially for low credit risk countries and during times of heightened market uncertainty

2 The particularity of these EM capitalisation-weighted indexes is that they are mainly composed of US dollar-denominated debt instruments issued by sovereign or quasi-sovereign entities. Moreover, not all the new EU countries are included in the EM Indexes for a long enough period to justify a separate analysis of those countries as a group. Nevertheless several panel-based approaches have tried to address the above mentioned shortcomings and to draw conclusions at the country-level.
} 
market assessment of a country's creditworthiness most probably reflects non-fundamentals factors, i.e. global conditions and market imperfections, in particular potential spill-over effects.

More recently, EMBI Global data are also used by Ciarlone, Piselli and Trebeschi (2007) to disentangle the respective roles of common factors and fundamentals in driving EMEs spreads since the beginning of the financial turmoil in summer 2007 onwards. To this end they develop a panel-co integration, fully modified-OLS approach to model spreads, with commonalities in spreads variability extracted through a principal component analysis. The study finds evidence of a common factor, reflecting changes in global financial conditions and their subsequent impact on the world economy that has accounted for over $80 \%$ of the rise in EMEs spreads during the financial turmoil, thus making these countries vulnerable to shifts in market confidence. Additionally, countryspecific sources of vulnerability play also a role, either as independent sources of shocks or by conditioning countries' responses to a global shock. In particular, they find that already deteriorated fundamentals in the run-up to the financial market turmoil in some emerging countries are the main sources of vulnerability to a sudden reversal in international capital flows.

Other recent studies have tried to investigate the part of spreads left unexplained by the decomposition into default and liquidity factors and mainly attributed to unobserved factors driving EMEs spreads movements. Hauner, Jonas and Kumar (2007) studied the notion of policy credibility that the new EU countries may have experienced since they joined the EU in May 2004. To this end, the authors check for credibility effects in particular on the fiscal front in sovereign credit by controlling for other possible factors that could differentiate the new EU countries from other EMEs. The former appear to have enjoyed higher credibility in the run-up to their accession, compared to other EMEs, which could explain the apparent discrepancy, in some countries, between their weak fiscal and external positions and limited market concerns.

An important role in driving EMEs bond spreads is sometimes attributed to political factors as in the study by Baldacci, Gupta, and Mati (2008). On a panel of 30 emerging market economies from 1997 to 2007, they show that, apart from macroeconomic policies, liquidity and the degree of financial deepening, the interaction between fiscal and political factors are important determinants of country risk premia.

Finally, one attempt to treat the new EU countries as a group in order to analyse government bond yields is proposed by Koukouritakis and Michelis (2008). The possibility of short and long-run interdependencies among the new EU countries term structures of interest rates are investigated based on a multi-step co-integration and Granger causality approach. Even if the expectations theory is confirmed for almost all countries, there is evidence of overall weak short-run and long-run interdependency among countries' term structures. However, sub-groups of countries seem to display stronger interdependency in their term structure than others as their monetary policy strategies show a higher degree of similarity in the short and the long-run than at the whole NMS group level.

Against this background, the present paper aims at filling the gap in the literature by proposing a novel approach to analyse the developments of long-term interest rates in eight new EU countries (Bulgaria, Czech Republic, Latvia, Lithuania, Hungary, Poland, Romania and Slovakia), relative to euro area average long-term benchmark yields. We use the PMG methodology to identify a dynamic error correction model with long-run commonalities and short-term differences in coefficients and error variances at the country level to investigate the empirical determinants of government bond spreads in the new EU countries as a group. Although the PMG methodology has already been used to analyse spreads in the EMEs (for instance, Ferrucci, 2003), this is to our knowledge the first attempt to apply it specifically to new EU countries' government bond spreads.

The estimated model would thus enable us to assess the role of fundamentals in conditioning the cost of long-term borrowing, with implications for policy prescriptions, in particular taking into account the nominal convergence criteria laid down by the Maastricht treaty which must be satisfied before a candidate country can join the European Monetary Union (EMU). ${ }^{3}$ In this paper we consider the convergence of ten-year government bond yields to the euro area average. This approach is also used in the Convergence Report of the ECB when it deals with the assessment of the durability and sustainability of the convergence process of the countries under examination. The estimations also provide an operational framework in order to quantify the permanent and

\footnotetext{
${ }^{3}$ To be more precise, according to the long-term interest rates criterion, Member States under examination should have, over a period of one year before the examination, an average nominal long-term interest rate that does not exceed by more than 2 percentage points that of, at most, the three best performing Member States in terms of price stability.
} 
temporary impact of idiosyncratic and common shocks on new EU countries' government bond spreads at a given point in time. Furthermore, we identify two sub-groups of countries, characterised by high and low current account imbalances that seem to converge to different equilibrium values and highlight their respective determinants.

\section{Methodological issues and data description}

\subsection{The model}

Yield differentials reflect the premium required by investors to hold government securities issued by new EU countries compared to equivalent bonds issued by the euro area member states. This compensation reflects the credit (default) risk, liquidity and exchange rate risk, as well as other factors like transaction costs and market behaviour.

As regards the default risk, when investors put into question the government's ability to repay its outstanding debt on time, the yield on government bonds will rise in order to compensate debt holders for the increased risk. The liquidity and exchange rate risks refer to the barriers in the secondary market to trading domestic currency-denominated assets, whereas the transaction costs refer to inefficiencies introduced by cross-border payments and securities settlement as well as by differences in taxation, standards and legislation.

To assess the determinants of government bond spreads we adopt a dynamic panel approach that accounts for the specificity of the new EU countries spreads, namely non-stationarity and a considerable amount of persistence. A good explanatory model of government bond spreads should be flexible enough to both incorporate the adjustment trend to equilibrium values over medium to long-run (during what we call the "convergence process") and heterogeneous short-run dynamics at country-level.

In the literature there are already a large number of dynamic panel estimators. For our purposes the pooled mean group technique (PMG) developed by Pesaran, Shin and Smith (1999) seems to be an appropriate approach. Indeed, this method is particularly fit for panels composed of a small number of countries, expected to show some similarities in the specifications and parameters but that also differ in some respects. This estimation approach is an intermediate solution that reconciles pooled estimates, where parameters are constrained to be the same across countries, and mean group ones, based on separate countries regressions.

As showed by Baltagi and Griffin (1997) and Boyd and Smith (2002), the hypothesis of long-run homogeneity leads to more stable and economically plausible estimates than an error correction model performed on individual series. Pooling countries together in the long-run specification also addresses the cross-section heteroskedasticity problem that occurs in heterogeneous panels i.e. the fact that the cross section tends to vary with the error term, leading to spurious linear regressions. At the same time, as Haque, Pesaran and Sharma (2000) pointed out, neglecting cross-country heterogeneities in the short-run can lead to misleading inferences in the long run. The large enough cross sections of country series allow us to carry out estimates of individual equations in the shortrun, thus separating the short-run dynamics from their adjustment towards the long-run equilibrium.

Based on the existent literature on the determinants of government bond spreads reviewed in Section 2, yield differentials relative to the euro area average are explained in terms of domestic fundamentals and a (euro area) common factor.

$$
\text { Spreads }=f(\text { Fundamentals, } \text { CommonFactors })
$$

We start from an autoregressive distributed lag specification of order $\mathrm{p}$ and $\mathrm{q}\left(\operatorname{ARDL}\left(p, q_{1}, . ., q_{n}\right)\right)$ according to which spreads are explained by their own lags as well as by the lags of their fundamental and common determinants in order to capture persistence effects (see also Pesaran and Shin, 1999).

Given data on time periods $t=1,2, \ldots T$ and groups of countries $i=1,2, \ldots N$, the autoregressive distributed lag $A R D L\left(p, q_{1}, . ., q_{n}\right)$ specification can be written as follows, where $n$ is the number of explanatory variables:

For each country $i$ at time $t$

$$
\text { Spreads }_{i t}=\mu_{i}+\sum_{j=1}^{p_{i}} \lambda_{i j} \text { Spreads }_{i t-j}+\sum_{j=0}^{q_{1 i}} \delta_{i j}^{(1)} F_{i t-j}^{(1)}+. .+\sum_{j=0}^{q_{n i}} \delta_{i j}^{(n)} C_{t-j}+\varepsilon_{i t}
$$


where Spreads is the explained variable, in our case the monthly average spreads computed from yields on long term government bonds or proxies for convergence purposes (10-years) for the eight new EU countries relative to the average of the euro area longterm government bond yields, $F$ and $C$ denote the fundamentals and respectively the common factors, coefficients $\mu_{i}$ capture the fixed effects which varies across countries, while $\lambda_{i j}$ and $\delta_{i j}^{(1)}, \ldots \delta_{i j}^{(n)}$ are the coefficients on the $n$ lagged explanatory variables.

In Pesaran, Shin and Smith (1999) initial approach, the $A R D L$ model is estimated at country-level to detect the optimum lag lengths of the explanatory variables. This implies a different set of lagged dependent and explanatory variables $\left(p_{i}, q_{1 i}, \ldots, q_{n i}\right)$ across countries and a large number of coefficients to be estimated in the constrained model.

The spreads specification (equation (2)) can be re-parameterized by writing it in first differences as follows:

$$
\begin{aligned}
& \Delta \text { Spreads }_{i t}=\phi_{i} \text { Spreads }_{i t-1}+\gamma_{1 i}^{(1)} F_{i t}^{(1)}+\ldots+\gamma_{1}^{(n)} C_{t}+ \\
& \sum_{j=1}^{p_{i}-1} \lambda_{i j}^{*} \Delta \text { Spreads } s_{i t-j}+\sum_{j=0}^{q_{1 i}-1} \gamma_{2 i j}^{(1)} \Delta F_{i t-j}^{(1)}+\ldots+\sum_{j=0}^{q_{n i}-1} \gamma_{2 i j}^{(n)} \Delta C_{t-j}+\mu_{i}+\varepsilon_{i t}
\end{aligned}
$$

where the new coefficients on lagged levels and first differences $\phi_{i}, \gamma_{1 i}^{(1)} \ldots \gamma_{1}^{(n)}, \lambda_{i j}^{*}, \gamma_{2 i j}^{(1)} \ldots \gamma_{2 j}^{(n)}$ in equation (2.1) are function of the initial ones in the $\operatorname{ARDL}\left(p, q_{1}, . ., q_{n}\right)$ model (equation 2):

$$
\begin{gathered}
\phi_{i}=-\left(1-\sum_{j=1}^{p_{i}} \lambda_{i j}\right), \lambda_{i j}^{*}=-\sum_{m=j+1}^{p_{i}} \lambda_{i m} \text { for } j=1,2, \ldots p-1 \\
\gamma_{1 i}^{(1)}=\sum_{j=0}^{q_{1 i}} \delta_{i j}^{(1)}, \ldots, \gamma_{1 i}^{(n)}=\sum_{j=0}^{q_{n i}} \delta_{i j}^{(n)} \\
\gamma_{2 i j}^{(1)}=-\sum_{m=j+1}^{q_{1 i}} \delta_{i m}^{(1)}, \text { for } j=1,2, \ldots q_{1 i}, \ldots, \gamma_{2 i j}^{(n)}=-\sum_{m=j+1}^{q_{n i}} \delta_{i m}^{(n)}, \text { for } j=1,2, \ldots q_{n i}
\end{gathered}
$$

Finally, the previous equation can be rearranged under the form of an error correction equation, according to which the variation of spreads in any period is related to previous periods' gap from the long-run equilibrium values, at a speed dictated by a countryspecific error correction term:

$$
\begin{aligned}
& \Delta \text { Spreads }_{i t}=\phi_{i}\left(\text { Spreads }_{i t-1}-\alpha_{i}-\beta_{i}^{(1)} F_{i t-j}^{(1)}-\ldots-\beta_{i}^{(n)} C_{t}\right)-\sum_{j=1}^{p_{i}-1} \lambda_{i j}^{*} \Delta \text { Spreads }_{i t-j}- \\
& -\sum_{j=0}^{q_{1 i}-1} \gamma_{2 i j}^{(1)} \Delta F_{i t-j}^{(1)}-\ldots-\sum_{j=0}^{q_{n i}-1} \gamma_{2 i j}^{(n)} \Delta C_{t-j}+\varepsilon_{i t}
\end{aligned}
$$

The term in brackets is the long-run relationship, with $\alpha_{i}$, the country-specific intercept and $\beta_{i}^{(1)}, \ldots, \beta_{i}^{(n)}$ the long-run coefficients on the explanatory variables or the sensitivities of the government bond spreads to changes in fundamentals and common external factors :

$$
\beta_{i}^{(1)}=-\frac{\gamma_{1 i}^{(1)}}{\phi_{i}}=\frac{\sum_{j=0}^{q_{1 i}} \delta_{i j}^{(1)}}{1-\sum_{j=1}^{p_{i}} \lambda_{i j}}, \ldots, \beta_{i}^{(n)}=-\frac{\gamma_{1 i}^{(n)}}{\phi_{i}}=\frac{\sum_{j=0}^{q_{n i}} \delta_{i j}^{(n)}}{1-\sum_{j=1}^{p_{i}} \lambda_{i j}}, \alpha_{i}=-\frac{\mu_{i}}{\phi_{i}}=\frac{\mu_{i}}{1-\sum_{j=1}^{p_{i}} \lambda_{i j}}
$$

In equation (3), $\phi_{i}$ denotes the error correction coefficient or the speed of adjustment to equilibrium values, assumed to be different across countries.

Furthermore, while allowing for differences in intercepts, short-run coefficients and error variances, the PMG approach constrains the long-run slope coefficients to be the same across countries. Given our model, the assumption of long-run homogeneity across countries can thus be written: 


$$
\beta_{i}^{(1)}=\beta^{(1)}, \ldots, \beta_{i}^{(n)}=\beta^{(n)}
$$

Due to data limitations in the case of some of the new EU countries spreads relative to the euro area (between 41 observations for Romania and 110 observations for the Czech Republic), we impose a uniform one-lag structure $A R D L(1,1, . ., 1)$ for all countries and variables entering the model. The initial PMG model was run with fewer variables and different lag structures and one lag seems to be a good compromise that allows us to spare enough degrees of freedom in the lag specification and to take into account all economically meaningful determinants of spreads. Appendix 1 presents the results of the augmented Dickey-Fuller test and the more elaborate modified Dickey-Fuller test for a unit root in which the series are transformed by a generalized least-squares regression. Only in 5 cases out of 88 the tests enabled to reject the null hypothesis that the variable contains a unit root, thus justifying our assumption that all the variables are $I(1)$.

In the case of an $A R D L(1,1, . ., 1)$, the model to be tested can be written:

$$
\Delta \text { Spreads }_{i t}=\phi_{i}\left(\text { Spreads }_{i t-1}-\alpha_{i}-\beta_{i}^{(1)} F_{i t}^{(1)}-\ldots-\beta_{i}^{(n)} C_{t}\right)-\gamma_{2 i 0}^{(1)} \Delta F_{i t}^{(1)}-\ldots-\gamma_{2 i 0}^{(n)} \Delta C_{t}+\varepsilon_{i t}
$$

where

$\phi_{i}=-\left(1-\lambda_{i 0}\right), \alpha_{i}=\frac{\mu_{i}}{1-\lambda_{i 0}}, \quad \beta_{i}^{(1)}=\frac{\delta_{i 0}^{(1)}+\delta_{i 1}^{(1)}}{1-\lambda_{i 0}}, \ldots \beta_{i}^{(n)}=\frac{\delta_{i 0}^{(n)}+\delta_{i 1}^{(n)}}{1-\lambda_{i 0}}$

restricted in the long-run to satisfy the slope homogeneity condition :

$$
\beta_{i}^{(1)}=\beta^{(1)}, \ldots, \beta_{i}^{(n)}=\beta^{(n)}
$$

according to the PMG methodology.

Moreover, for a long-run relationship to exist, the error correction coefficients have to be different from zero:

$$
\phi_{i} \neq 0 \text {, for all } i
$$

\subsection{Choice of variables}

Our dependent variable is given by monthly average spreads computed from yields on harmonised long-term government bonds relative to the long-term euro area average yield, for the following eight countries: Bulgaria, Czech Republic, Hungary, Latvia, Lithuania, Poland, Slovakia and Romania. ${ }^{4}$ We calculate the spreads against the euro area average in line with the analysis regularly done by the Eurosystem to assess the durability and sustainability of the convergence process of the countries under examination.

Figure 1 illustrates the evolution of spreads on long-term government bonds for the eight new EU countries relative to the euro area average, over the period January 2003 to December 2008.

Overall, for most of the countries that we are analysing, although to a different degree, spreads experienced a downward trend from mid-2001 to mid-2007 in the context of ample and favourable global liquidity conditions, low investors' risk aversion and positive economic activity at domestic level due to formal prospects for these countries to join the EMU. In mid-2007 spreads started rising albeit staying at lower levels than those reached in the 2000-2001 period. The pace of an increase accelerated during 2008 as the financial turmoil became more widespread. It appears that the most affected countries are those which have already displayed in the past high and considerable volatile levels on their spreads relative to those in the euro area.

\footnotetext{
${ }^{4}$ Interest rates have been measured on the basis of available harmonised long-term interest rates, which were developed for the purpose of examining the convergence process as in Article 4 of Protocol No 21 on the convergence criteria referred to in Article 121 of the Treaty. Appendix 1 contains a more detailed description of the whole dataset.
} 


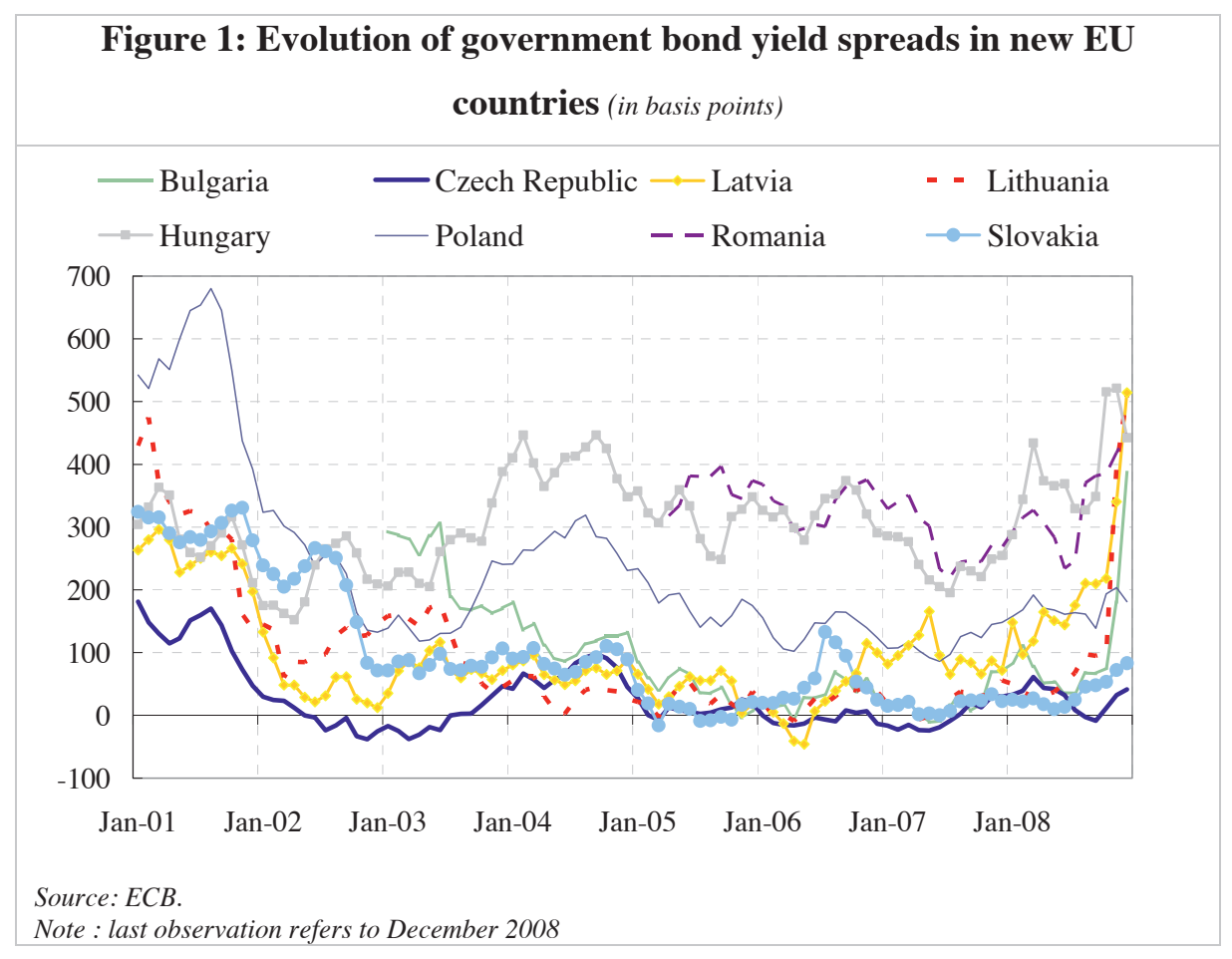

At the same time, spreads in the eight new EU countries are characterised by a considerable amount of heterogeneity. Countries like Poland and the Czech Republic have experienced significant declines since 2001 which were only partially reversed in the period of the financial crisis. Furthermore, for a few countries like Romania and Lithuania the levels observed at the end of 2008 are the historical maximum levels, and the same holds for Hungary, Latvia, and Bulgaria. These changes reflect mainly deteriorating economic outlook and external conditions as well as difficulties in fulfilling funding needs as a result of spill-over effects from the tighter financing conditions in the euro area.

Even though there is some co-movement of long-term government bond spreads of the new EU countries discernible in Figure 1, there is also some divergence which may be due to differences in credit risk perceptions reflecting differences in domestic macroeconomic policies which could be eventually priced in by the market.

The explanatory variables that enter our analysis of new EU government bond spreads were selected based on the convergence criteria and on the existing literature on spreads determinants in emerging economies as already mentioned above. Since the perspective of this paper is mainly empirical, we take into account variables for which available data exist and are easily obtainable.

We group the explanatory variables according to their possibility to explain country differences in fiscal, external and money market conditions as well as country differences in the nominal convergence and in their international openness. We take into account also a common factor related to the financial market conditions in the euro area. The pairwise correlations provide a first look at the contemporaneous relationship between yield differentials and their potential determinants. The correlations matrices (see Appendix 1) highlight a considerable amount of heterogeneity in individual countries sensitivities to fundamentals and the common factor. This feature suggests that the short-run dynamics in the PMG model should capture the heterogeneous adjustment to the equilibrium levels.

More specifically, we consider the following explanatory variables:

\section{- Fiscal fundamentals}

A first set of variables is representative of countries' fiscal balance sustainability. First, we use the ratio of fiscal balance to GDP that is expected to have a negative impact on spreads ${ }^{5}$. As yield differentials are computed over the euro area, we expect that higher divergence of the fiscal balance from the bottom limit set through the Stability and Growth Pact (i.e. if deficits breach the 3\% of GDP reference value) leads to an increase in government bond spreads. Indeed, these spreads for Slovakia, Lithuania, Latvia and Bulgaria

${ }^{5}$ See Afonso et al. (2007) and Schuknecht, von Hagen and Wolswijk (2008). 
are highly negatively correlated with the fiscal balance-to-GDP ratio (Akitoby and Stratman, 2008). It has been seen in the literature that fiscal variables can act as main components of policy credibility when explaining the determinants of sovereign credit (Hauner, Jonas and Kumar, 2007).

Another important indicator for the convergence analysis is the general government consolidated gross debt in accordance with the excessive deficit procedure as a percentage of GDP. Higher public indebtedness increases the risk of default on sovereign debt and translates into higher spreads on government bonds. ${ }^{6}$ As pairwise correlations at the country level show (see Appendix 1), there is evidence of a strong positive relationship between spreads and the government debt-to-GDP ratio, particularly in Bulgaria, Lithuania and Slovakia

We also consider the amount outstanding of general government sector interest payments on public debt as a ratio to GDP that is likely to provide information on government's liquidity apart from its solvency reflected in the levels of domestic and external debt. Interest payments or the government debt service have been previously used in the empirical literature on yield differentials as part of countries gross financing needs (see e.g. Ferrucci, 2003, Bernoth, Hagen and Schuknecht, 2006). We expect that markets show a more immediate reaction to changes in interest payments made on public debt, than to changes in the principal, as confirmed by the positive and high correlations with government bond spreads in the case of Lithuania, Poland, Slovakia and Romania.

\section{- $\quad$ External position}

A second set of variables characterises the countries' external solvency. A first measure expected to play an important role in driving government bond yield differentials is the current account balance-to-GDP ratio (see Strahilov, 2006). The lower the current account balance, the more the economy relies on capital inflows (net borrower) and the more it is perceived as vulnerable to reversals in international flows of funding. Spreads will therefore tend to widen to offset the equivalent rise in default risk on public debt. Pairwise correlations at the country level already confirm the expected negative sign for Hungary, Slovakia and for the Czech Republic. A second measure of countries' external position is the gross external debt-to-GDP ratio. As in the case of government debt-to-GDP ratio, higher external indebtedness, both public and private, is expected to heighten markets' perception of default, putting upward pressure on spreads.

\section{- Country openness}

Related to countries' external solvency is the degree of countries' openness to trade and financial flows. Generally, an open economy is able to generate the required trade surpluses in order to refinance the present stock of debt or to finance new debt. In the literature on spreads determinants, country openness is showed to play an important role in explaining emerging economies' cost of borrowing as the penalty for sovereign default is higher in terms of capital reversion in an open rather than a closed economy (see Ferrucci, 2003). For our analysis, we compute a measure of trade openness as the sum of imports and exports as ratio to GDP. Based on pairwise correlations, the expected negative relationship holds for Bulgaria, Poland, Slovakia, Lithuania, and to a lower extent for Latvia.

\section{- Inflation rate}

Actual realized inflation rates are taken into account. The domestic rate of inflation has been viewed in the literature on the determinants of spreads as a proxy for the quality of economic management thus positively influencing the sovereign default risk (Min, 1998). In the case of emerging economies, inflation is also showed to be a leading indicator of balance of payment crises ${ }^{7}$ thus $^{-1}$ also positively influencing sovereign default risk. Furthermore, an increase in the inflation rate increases the probability of the central bank performing a tighter monetary policy which could put upward pressure on government bond yields and thus the spreads could widen.

However, given the specificity of new EU countries, a negative relationship between inflation and long-term interest rates differentials is also plausible. Under the uncovered interest rate parity, the interest rate differential reflects the expected change in the exchange rate over the life of the bond. However in the case of the new EU countries, the real exchange rate variation can be driven

${ }^{6}$ For previous studies using this variable see for instance Lonning (2000), Ferrucci (2003), Schuknecht, von Hagen and Wolswijk (2008).

${ }^{7}$ See, among others, Eichengreen, Rose and Wyplosz (1995). 
by either permanent or transitory factors. Among the permanent factors, productivity, per capita income and foreign capital inflows play an important role whereas fiscal shocks are mainly seen as transitory in driving the exchange rate dynamics. As showed in the literature on inflation determinants in the Central European Countries (see for instance Mihaljek and Klau, 2008), more structural factors, in particular the Balassa-Samuelson effect- rather than financial ones- seem to drive inflation rates in these economies.. As a consequence, whenever, the rise in inflation is perceived by investors as having a structural rather than transitory source, higher inflation may well coexist with lower long-term interest rate differentials.

\section{- $\quad$ State of real convergence}

We use the gross national income per capita as a measure of the catching-up process to euro area living standards that has characterised the new EU countries in the last decade. We expect that spreads tighten in a context of improved real convergence. At country-level, the negative correlation is confirmed for Bulgaria, Czech Republic, Romania, Poland, Slovakia and Lithuania. Hauner, Jonas, and Kumar (2007) showed that an increase in per capita income used as a proxy for institutional quality can lead to higher credit ratings and thus lower sovereign spreads.

\section{- Exchange rate level}

The new EU countries of our sample are characterised by different degrees of exchange rate variability. Some of them (Bulgaria, and also Slovakia, Latvia and Lithuania) have adopted an exchange rate targeting regime, either in the form of a currency board regime in the aftermath of currency crises in mid-1990s (Bulgaria, Latvia and Lithuania) and replaced by a narrow fluctuation band under ERMII (the case of Lithuania and Latvia as of June 2004 and respectively May 2005), or directly joining the ERMII system after years of managed floating of their currency (the case of Slovakia as of November 2005).

The remaining four countries of our sample (Czech Republic, Hungary, Poland and Romania) have adopted various types of inflation target to support their primary monetary policy objective ${ }^{8}$, thus allowing more flexibility to their exchange rate in order to stabilise the economy. Our objective is to quantify the impact of exchange rate fluctuations on spreads for countries that do not specifically target the exchange rate, without splitting the sample or include categorical variables. At country level, pairwise correlations indicate different reactions to changes in the exchange rate level according to country as this can be affected not only by market pressures but also external conditions. Overall, it has been shown however that there should be a positive relation between changes in the exchange rate and government bond spreads as pronounced volatility and depreciation in the value of the exchange rate can lead to higher spreads (Favero, Giavazzi and Spaventa, 1997).

\section{- Money market rates}

According to the expectations theory (which has been empirically supported for the new EU countries by Koukouritakis and Michelis (2008)), long-term government bond yields are a function of short-term rates (current and expected). In this respect we include in our analysis a measure of money market conditions calculated as the spreads between domestic short-term money market rates and euro area money market rates (EURIBOR). This proxy for domestic money market liquidity may also provide information on the liquidity conditions in the long-term segment. ${ }^{9}$ At the country level the positive relationship is confirmed in the case of Poland, Slovakia, Lithuania and Hungary. Moreover, it has been shown that the magnitude of the positive relationship between short and long term liquidity premia is contingent upon the economic environment. ${ }^{10}$

\section{- Common (euro area) factor}

\footnotetext{
${ }^{8}$ For instance, in the Czech Republic the target band of 3.5\%-5.5\% set for December 2000, has been progressively narrowed to 3\%-5\% in January 2002, 2\%-4\% in January 2005 and replaced by a 3\% point target for headline inflation as of January 2006. Hungary has adopted the inflation targeting regime in June 2001 with the medium-term point inflation target continuously lowered from $7 \%$ in 2001 to $3 \%$ for the period starting in 2007 . After five years of direct inflation targeting, Poland adopted at the beginning of 2004 a continuous inflation target of $2.5 \%$. Finally, in Romania, the inflation targeting was adopted in August 2005 with targets set to decline from $7.5 \%$ in 2005 to $3.8 \%$ in 2008 .

${ }^{9}$ See Beber, Brandt and Kavajecz (2008).

${ }^{10}$ See Goyenko, Subrahmanyam, and Ukhov (2008) for an analysis of the term structure of bond market liquidity.
} 
Finally, we take into account a proxy for global financial conditions that may affect government bond spreads. The common factor is proxied by the implied stock market volatility of the Dow Jones Eurostoxx 50 index. We assume that the sensitivities of government bond spreads of the new EU countries to changes in equity market volatility on euro area markets may reflect portfolio reallocations between bonds, equity and cash. We assume that global investors are diversified across these three asset classes and they treat differently the euro area and new EU member states assets; furthermore the average long-term interest rate on euro area government bonds is seen as a benchmark for the new EU member states' bonds. For instance, an increase in euro area stock market volatility leads to an increase in the overall risk of global portfolio that will require rebalancing towards fixed income securities (part of them issued by the new EU member states) in two different ways. On the one hand, it is possible that investors increase their demand for bonds of new EU member states (or only for those seen as less risky among the group of countries) thus lowering the yield differential relative to the euro area benchmark. On the other hand, if the negative wealth effects associated with the global rise in risk aversion are too strong, markets can react by shedding either all kinds of risky assets in an indiscriminate move (flight to quality/liquidity) or only the government bonds that are seen as riskiest among the new EU members states fixed-income asset class. ${ }^{11}$ In the empirical literature on government spreads, Ferrucci (2003) found a strong empirical relationship between spreads and external factors such as US equity prices and Beber, Brandt and Kavajecz (2008) used the VIX and VSTOXX indices to show that higher volatility leads to wider government spreads.

\section{Empirical results}

As a preliminary step, we run the pooled mean group estimations based on a $A R D L(1,1, . ., 1)$ specification which takes into account the above listed determinants of spreads, one by one, independently of the other variables eventually included in the specification. This can provide initial information as to the role of these variables in the long-run even if their final impact may also depend on the correlation with the set of other spreads determinants. The results are presented in Appendix 2. All the variables, with the exception of fiscal balance are significantly different from zero in the long-run. Moreover, negative and statistically significant error correction coefficients for variables like external debt and interest payments on government debt-to-GDP ratios, EURIBOR spreads and euro area equity market volatility suggest that they may represent, already at this stage, a plausible explanation for the long dynamics of spreads.

In the case of the other variables that display the expected sign in the long-run, although not different from zero, the results tend to suggest that their impact will depend on the long and short-run specifications used to explain spreads. Overall, the long-run signs seem to confirm our intuitions and motivate their inclusion into the initial specification of the main model.

The results presented in this section are based on the PMG estimation of equation (4), restricted in the long-run by the constant slope condition (4.1), either on the initial group of eight countries or for the two country clusters we will determine later on in this section. The estimated panel error-correction model is a re-parameterised $A R D L(1,1, . ., 1)$ model of government bond spreads assumed to be driven by a set of fundamentals and common factors.

As for the choice of variables to be included in our model, we employed the following methodology. We start with the whole set of 10 variables (government debt-to-GDP, interest payments-to-GDP, fiscal balance-to-GDP, trade openness, current account balance-to-GDP, income per capita, inflation rate, exchange rate, short-term interest rates differentials as well as the euro area equity market volatility as common factor), with which we reasonably expect to capture most of the variation in spreads, both in the long-run and the short-run. While keeping them all in the short-run (in first differences, according to the underlined $A R D L(1,1, . ., 1)$ specification), to facilitate the individual countries spreads adjustment to the equilibrium values, we drop from the long-run specification the variables that are not meaningful from an econometric point of view one by one and by trying different combinations through an iterative procedure. ${ }^{12}$

\footnotetext{
${ }^{11}$ See Bunda, Hamann, Lall (2009) for a conceptual framework of investors' behaviour as regards emerging markets government bonds.

${ }^{12}$ The criterion consists in keeping a variable in the long-run specification if it was meaningfully signed from an economic point of view and if the new long-run path implies country-specific error correction coefficients negative and significantly different from zero.
} 
The technique developed by Pesaran, Shin and Smith (1999) does not necessarily require preliminary tests for nonstationarity. As showed by Pesaran and Shin (1999), the ARDL approach has the additional advantage of yielding consistent estimates of the long-run coefficients that are asymptotically normal, irrespective of whether the underlying regressors are I(1) or $\mathrm{I}(0)$. The approach can thus be implemented whatever the integration order as it tests, in a first step, whether a long-run relationship exists between variables i.e. whether the variables are co-integrated, and in the second step, it detects the optimum lag structure of the model. We use a simplified $A R D L(1,1, . ., 1)$ specification for government bond spreads that assumes that they are non stationary and integrated at order one, in line with the results of unit root tests performed on all series used in the paper (see Tables A1.1-2 in Appendix 1). Once a co-integrating relationship is found among the non-stationary variables in the model, the PMG procedure estimates the long-run relationship and the short-run dynamics in the form of an ECM framework (equation (4)).

\subsection{Long-run determinants and short-run dynamics}

The results of pooled mean group estimation for the group of eight new EU countries are given in Table 1a (Long-run determinants) and Table 1b (Error correction coefficients and short-run dynamics). The estimation period is January 2001 until December 2008 (see Appendix 1 for data availability). As main long-run determinants of government bond spreads the models has picked up the sustainability of external finances (as reflected by the significant positive coefficient on external debt-to-GDP ratio), short-term interest rate spreads, as reflected by the significant positive coefficient, the exchange rate (negative coefficient), inflation rate (positive coefficient) and ), the fiscal balance and the euro area equity volatility, through both are entering with non-significant negative coefficients. Trade openness is a key variable to external solvency of a country in the sense that a high degree of openness may indicate that the required expected trade surpluses to meet future foreign debt repayments may materialize and therefore this tends to reduce bond spreads. For the long-run relationship to be valid, the error correction coefficients have to be different from zero for each country. As it is the case in Table 1b. Latvia, Bulgaria, Lithuania and the Czech Republic exhibit the lowest error correction values (below -0.1), suggesting that at constant long-run coefficients on fundamentals and on the common factor, as imposed by the PMG estimation, their government bond spreads would be relatively less affected in the long run by changes in the underlying fundamental determinants. Conversely, Poland, Slovakia, Hungary and Romania display higher error correction coefficients. This implies that the market perception on the quality of their fundamentals or the impact of the external environment are likely to have a bigger long-lasting impact on spreads in these countries rather than in those characterised by lower error correction coefficients. In particular, a simple calculation indicates that an adverse $10 \%$ shock to external indebtedness ratio, for instance, is likely to increase the long-run equilibrium spreads by 11 b.p. in Romania, 8 b.p. in Poland and Slovakia compared to 5 b.p. in Czech Republic, Lithuania and Hungary or only 2 b.p. in Latvia. However, it should be recalled that the full impact of shocks will have to take into account the transitory dynamics as well as spreads persistence and country-specific intercepts, as it will be shown later at the end of this section.

\begin{tabular}{|l|c|}
\hline \multicolumn{2}{|l|}{ Table 1a. Long-run determinants } \\
\hline \begin{tabular}{|l|c|}
\hline ExtDebt & $5.01 * * *$ \\
\hline FiscalBalance & -5.94 \\
\hline TradeOp & $-2.26 * *$ \\
\hline Inflation & $17.36 * * *$ \\
\hline Exch. rate & $-2.70 * *$ \\
\hline Short i.r.spread & $0.39 * * *$ \\
\hline EAequity vol & -0.98 \\
\hline
\end{tabular}
\end{tabular}




\begin{tabular}{|c|c|c|c|c|c|c|c|c|}
\hline \multicolumn{9}{|c|}{ Table 1b. Error correction coefficients and short-run dynamics } \\
\hline & BG & $\mathbf{C Z}$ & $\mathbf{L V}$ & LT & HU & PL & RO & SK \\
\hline Error correction & $-0.08^{* * *}$ & $-0.10^{* * *}$ & $-0.05^{* *}$ & $-0.09 * * *$ & $-0.10^{* * *}$ & $-0.16^{* * *}$ & $-0.21^{* * *}$ & $-0.17^{* * *}$ \\
\hline D.ExtDebt & -0.08 & 0.53 & -0.67 & -6.43 & 0.17 & -5.08 & $-4.58^{* *}$ & -0.56 \\
\hline D.int.paym. & -490.56 & $-717.12^{* * *}$ & 930.09* & -206.58 & 53.74 & $821.63^{* * *}$ & -614.22 & $391.80^{* * *}$ \\
\hline D.Fiscal Balance & $16.86^{* * *}$ & $9.24^{*}$ & $31.66^{* *}$ & 27.81 & -12.66 & $101.43^{* * *}$ & -5.33 & -1.80 \\
\hline D.TradeOp & $-2.11^{*}$ & 0.10 & -1.37 & $-5.20 * * *$ & 1.51 & $3.03^{* *}$ & 2.81 & 0.25 \\
\hline D.CA & $0.80^{*}$ & $-0.47^{*}$ & -2.07 & -0.30 & 2.91 & 0.84 & 3.49 & -0.14 \\
\hline D.Income & -141.03 & -7.74 & -117.73 & 0.15 & 65.56 & $-761.63^{* * *}$ & -415.08 & -158.50 \\
\hline D.Inflation & -3.69 & 2.93 & $-9.14^{* *}$ & $-11.99 *$ & 5.04 & $15.52^{* * *}$ & -0.76 & 3.05 \\
\hline D. Exch. rate & 44.08 & 0.52 & 3.45 & 3.68 & $8.10^{* * *}$ & $3.55^{* * *}$ & 1.13 & $5.20^{* * *}$ \\
\hline D.Short i.r.spread & $0.32^{* * *}$ & $0.22^{* * *}$ & $0.09 * * *$ & 0.13 & $0.19^{* * *}$ & $0.30 * * *$ & 0.01 & $0.31^{* * *}$ \\
\hline D.EAequity vola & $-1.60 * *$ & 0.39 & -0.80 & -0.72 & $1.89 * * *$ & $1.31^{* * *}$ & -1.31 & $0.49 *$ \\
\hline cons & 2.00 & $35.95^{* *}$ & 7.80 & 27.88 & 22.19 & $48.10^{* *}$ & $109.99 *$ & 60.70 \\
\hline
\end{tabular}

Note: D. is the first difference operator, ExtDebt denotes external debt-to-GDP ratio, int.paym. interest payments-to-GDP ratio, Fiscal Balance fiscal balance-to-GDP ratio, TradeOp is the sum of exports and imports-to-GDP, CA current account balance-to-GDP, Income logarithm of per capita income, Inflation, actual rates of inflation, Exch. rate exchange rate as an index (Jan- $00=100)$, Short i.r.spread short-term interest rates minus the three-month EURIBOR, EAequity vola euro area equity market volatility and cons country specific intercept.

$* * *$ indicates significance at $1 \%, * *$ indicates significance at $5 \%$ and $*$ indicates significance at $10 \%$.

In the short-run, government bond spreads show a considerable amount of heterogeneity in their adjustment to equilibrium values. By construction, the PMG approach imposes the same short-run specification for all countries; therefore meaningful coefficients for some variables in the first differences may coexist with economically implausible ones. However, removing these variables from the short-run specification would reduce the explanatory power of the whole model by allowing less short-term adjustment to the long-run equilibrium. It is important to recall that, even if the PMG approach imposes the same specification in the short-run for all countries, the pooled estimates of the long-run coefficients are unaffected by the signs of the same variables in the short-run specification.

Among the fiscal variables, interest payments on government debt-to-GDP ratio play a relatively important role in driving government bond spreads in Latvia, Poland and Slovakia. Fiscal balance-to-GDP ratio also enters with a positive and statistically significant sign for Poland, Latvia, Bulgaria and Czech Republic.

The countries' degree of trade openness plays a role in driving the short-run dynamics in spreads in Lithuania as well as in Bulgaria. This finding suggests that increased trade integration has helped facilitate the access to finance on the government bond markets for some of the new EU countries. In other countries, namely Poland, trade openness enters with a significant but positive coefficient suggesting that a higher exposure to capital flows (that accompanied the trade openness in the new EU countries) has tended to increase their sovereign risk. While it is true that higher trade openness implies that the country is more able to refinance its debt in the future by means of trade surpluses, the negative and significant coefficient on the current account balance-to-GDP ratio in the Czech Republic implies that country openness associated to a negative current account position may actually increase the longterm yield differential.

Per capita income variations are likely to affect market's assessment as regards government bonds in the short-run mainly in Poland, where the coefficient is statistically significant, and, to a lower extent, in Bulgaria, Romania, Latvia and Slovakia, though the coefficients are not significant. The results suggest that over the sample period, improvements in real convergence explain part of the transitory dynamics of spreads for these countries.

Inflation rates can affect the governments' creditworthiness in the Czech Republic, Hungary and Slovakia, although the coefficients are not significantly different from zero. In Poland, however, inflation enters with a positive and significant coefficient which could be interpreted that financial markets do regard the inflation target and the monetary policy stance accordingly of the central bank as very important determinants for government bond spreads. For Latvia and Lithuania and, to a lower extent, for Bulgaria, changes in inflation has the opposite impact on spreads, in the short-run, suggesting that for the new EU member states that target the exchange rate, inflation is seen mainly a structural phenomenon. 
As expected, the exchange rate has a positive coefficient for all countries and it is statistically significant for Hungary, Poland. This is also the case of Slovakia that has allowed some flexibility to the exchange rate and does not have a past of commitment to a hard peg even though it was in the ERMII mechanism for at least two years.

Finally, liquidity conditions in the money market as reflected in the 3 month EURIBOR spreads play an important role in driving the short-run dynamics of spreads. The coefficients are positive and significant for most countries, except Lithuania and Romania.

The common factor as captured by the volatility in the euro area equity market seems to have a different impact in the short-run on the new EU member states as reflected by the positive and statistically significant coefficients for Hungary, Poland and Slovakia and the negative ones for Bulgaria (statistically significant) but also for Romania, Latvia and Lithuania. This result points out the presence of possible investors' discrimination as regards bonds issued by the new EU member states, with bonds issued by countries characterised by a positive short-run coefficient being perceived as less risky than those characterised by a negative coefficient. This short-term feature along with an inconclusive impact in the long-run specification tends to support the idea that individual countries spreads may have a different resilience to common external factors in both the long and the short-run. This hypothesis is verified in the next section where we try to identify two groups of countries displaying different patterns in their equilibrium path and short-run dynamics.

Appendix 3a presents for each country the long-term path of government bond spreads based on the error correction specification (the grey triangle-line), along with the PMG model-based spreads (the grey circle-line) and actual spreads (the plain black line). Whenever estimated spreads are computed using only the error correction specification, they seem to best fit actual spreads in five out of eight cases, in particular for Bulgaria, Lithuania, Latvia, Hungary and Poland. For the other three countries (Czech Republic, Slovakia and Romania) long-term spreads are lower than actual ones suggesting that the transitory factors, unrelated to long-run fundamentals, may put upward pressure on their cost of financing.

\subsection{Do investors differentiate across the new EU countries?}

In this section we challenge the pooled mean treatment of the new EU countries in the long-run by trying to identify two subgroups of countries enjoying a different market perception. To put it differently, we investigate whether investors tend to discriminate across those countries, leading to two distinct equilibrium paths for sovereign bond spreads.

The evolution of spreads illustrated on Figure 1 in Section 3 may suggest that countries for which spreads are constantly higher throughout the sample period (e.g. Hungary, Romania) may be characterised by higher equilibrium level spreads than countries, such as the Czech Republic or Slovakia, where long-run spreads are small and closer to zero. If we assume that the convergence process will go beyond the medium-term, the pooled mean approach may leave aside some long-run determinants of the high levels of spreads recorded by some countries. This approach has already been suggested by Pesaran, Shin and Smith (1999) and can be implemented in the same model by modifying equation (4.1) to become

$$
\begin{aligned}
& \beta_{i}^{(1)}=\beta_{\text {group } 1}^{(1)}, \ldots, \beta_{i}^{(n)}=\beta_{\text {group } 1}^{(n)}, i=1, k(\text { group } 1) \\
& \beta_{j}^{(1)}=\beta_{\text {group } 2}^{(1)}, \ldots, \beta_{j}^{(n)}=\beta_{\text {group } 2}^{(n)}, j=k+1, n(\text { group } 2)
\end{aligned}
$$

Since our objective is to identify different long-run determinants that may drive the variation of two sub-groups of countries' spreads, we first tried to separate the initial group of eight countries, according to their relative position to the median of cross-country fundamentals. More precisely, for each fundamental in our model, we used the median value across the panel to split the sample into lower and respectively higher vulnerability countries. Given the two groups, we run then the PMG estimation on each of them and investigate whether there is a valid long-run relationship that better explains spreads at the sub-group rather than at the whole sample level. For instance, using external debt-to-GDP ratio the group with an average lower than the panel median (around $50 \%$ ) comprises Poland, Slovakia, the Czech Republic and Hungary whereas Latvia, Lithuania, Bulgaria and Romania fall in the group of higher external debt vulnerability. Using the inflation rate criterion, Bulgaria, Latvia, Hungary and Romania display relative higher rates than the rest of the sample. The current account-to-GDP variable indicates a separation of the sample with lower than median values 
(negative balance of 8\%) for Bulgaria, Lavia, Hungary and Romania and higher than median values for Czech Republic, Lithuania, Poland and Slovakia. When looking at the three criteria, the assignment of Lithuania and Hungary to a specific group is not clearcut. After running our model on two groups with variable composition, we decided to assign Czech Republic, Lithuania, Poland and Slovakia to the same group (Group 1) which is formed by countries broadly characterised by a sustainable current account balance and/or external debt-to-GDP ratios. These countries are also characterised by lower inflation rates. The high negative current account balance and/or high external debt group (Group 2) is made of Bulgaria, Latvia, Hungary and Romania, which are also characterised by relatively higher inflation rates. .Figures $2 \mathrm{a}-\mathrm{b}$ illustrate the position of the countries depending on the current account balance and external debt ratio and on the current account balance and inflation rate.

Figures 2a-b: External debt-to-GDP, inflation rate and current account balance-to-GDP
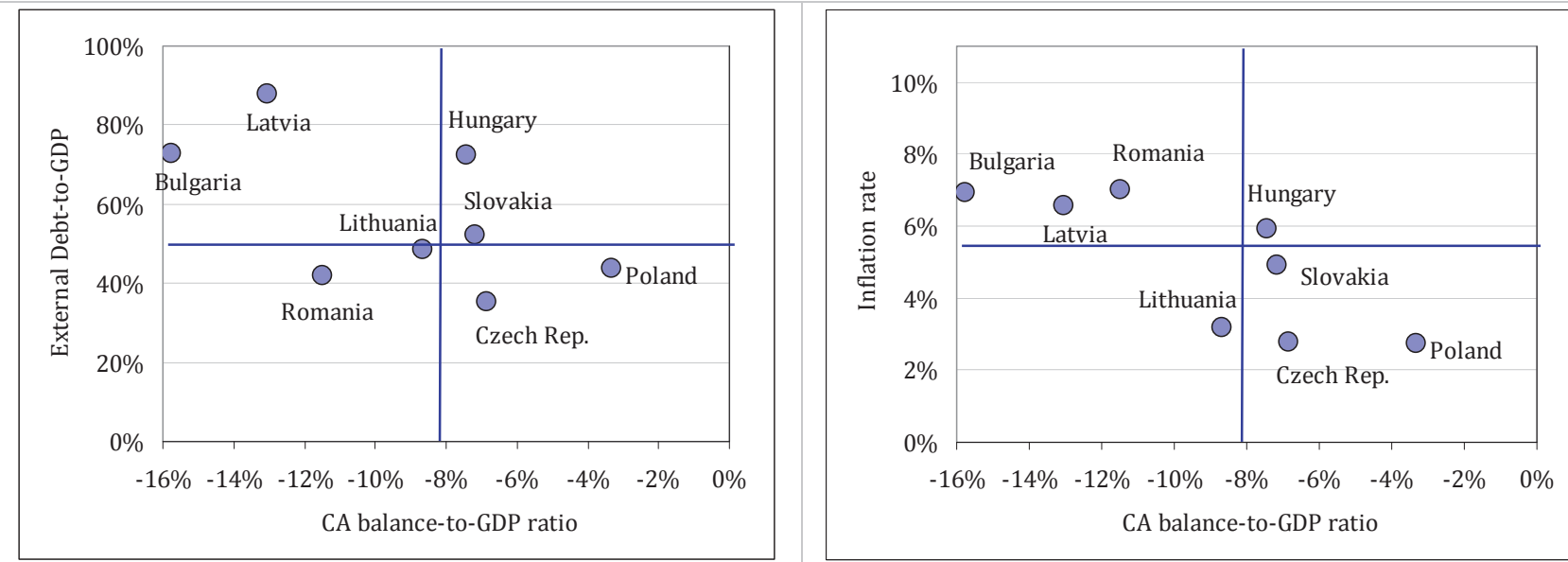

The evolution over the sample period of the two groups based on the current account balance criteria as well as the results of the PMG estimates are presented in Figure 3, for Group 1 (sustained current account balance, external debt and low inflation rates countries) and in Figure 4 for Group 2 (lower negative current account balance, higher external debt and inflation rates).

\section{Figure 3: Evolution of government bond spreads for country group 1 (in basis points)}

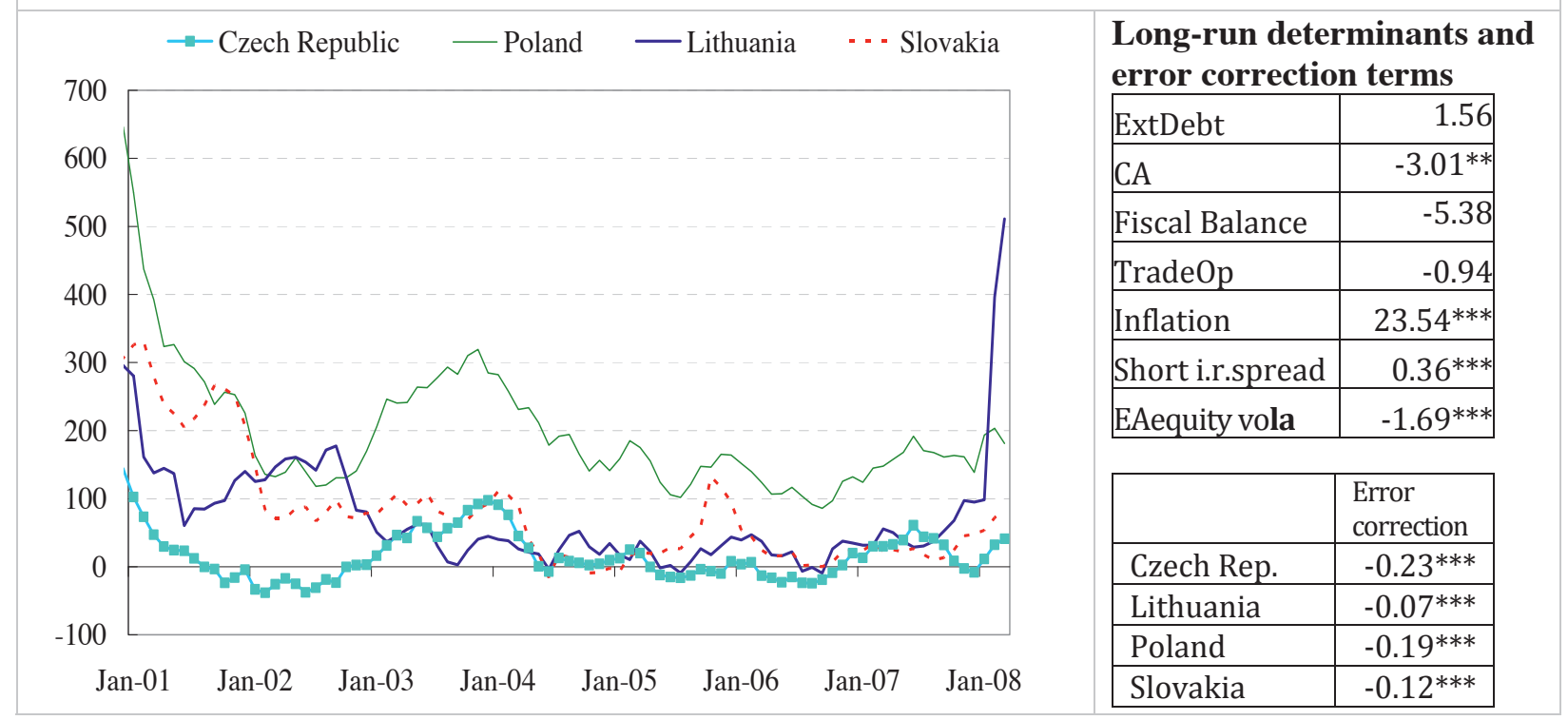

$* * *$ indicates significance at $1 \%, * *$ indicates significance at $5 \%$ and $*$ indicates significance at $10 \%$. 
For Group 1, the main drivers of the rise in spreads are inflation rates and short-term interest rates. Compared to the longrun results for the whole new EU member states group, the current account balance, previously found inconclusive, has now a role to play in driving spreads in these countries. Short-term interest rate differentials continue to drive spreads in the long-run and the common factor, the euro area equity market volatility, now enters with a negative and statistically significant sign in the long-run specification, suggesting that investors treat bonds issued by countries in this group in the same way as euro area government bonds. All the error correction coefficients are significant,, with Czech Republic adjusting faster to this equilibrium path than to the one estimated using the whole sample of countries.

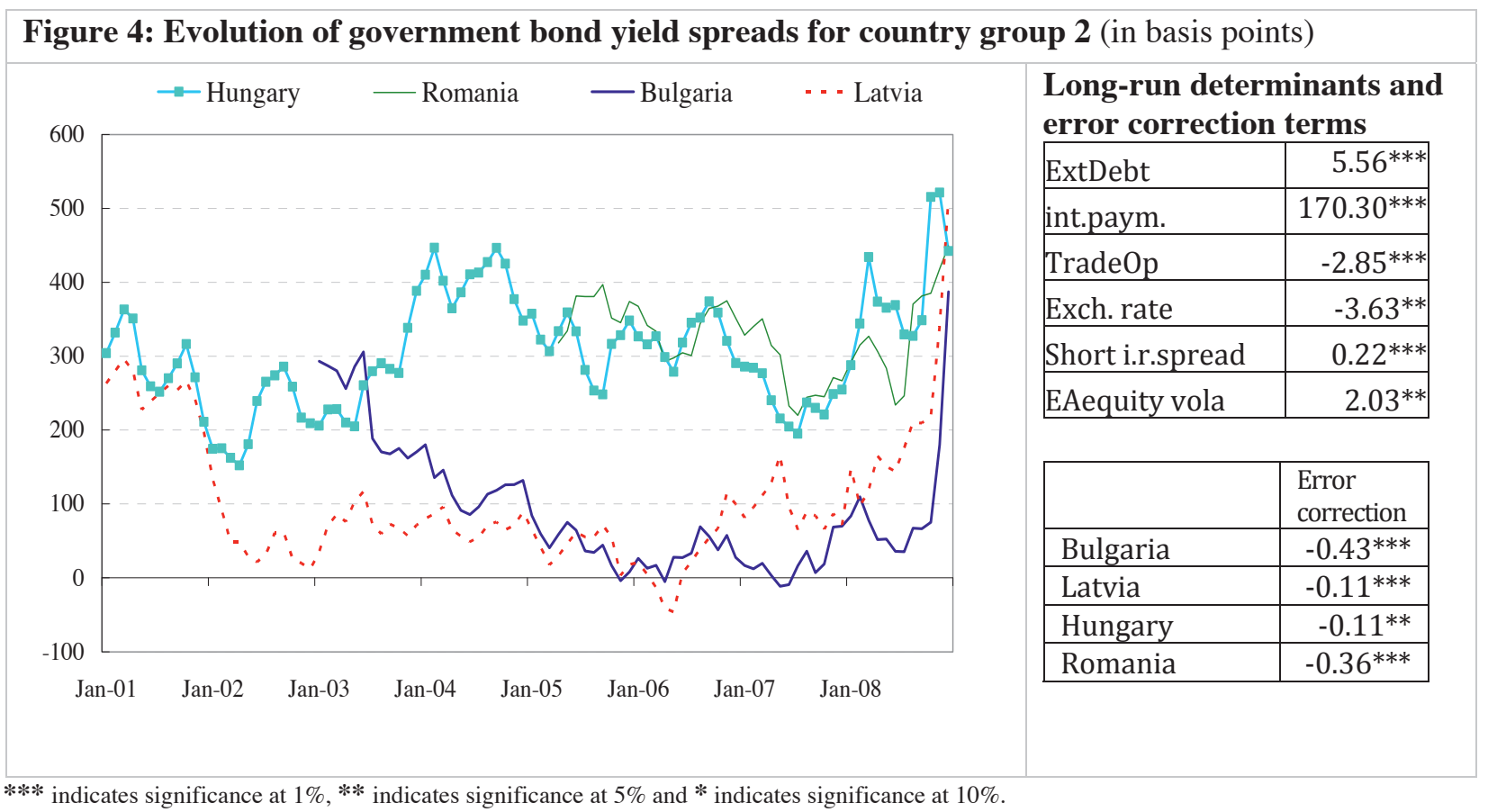

As far as the relatively higher negative current account balance-to-GDP, higher inflation and external debt group (Group 2) is concerned, fiscal fundamentals are among the drivers of bond spreads. In particular, while external debt-to-GDP ratio enters with a similar and statistically significant sign as for the whole group of countries, interest payments on government debt-to-GDP ratio become important in driving spreads in Bulgaria, Latvia, Hungary and Romania. Compared with the results for the whole group, the impacts of trade openness and exchange rate movements on spreads are confirmed. The main difference comes from the common factor which enters with a positive and statistically significant coefficient. The result suggests that investors may treat sovereign bonds issued by countries in this group as relatively riskier than those in the first one. All the error correction coefficients are negative and significant, with Bulgaria and Romania characterised by a considerably higher speed of adjustment to this equilibrium compared to the initial one (error coefficients of -0.43 and -0.36 for the subgroup specification compared to -0.08 and -0.21 respectively, for the estimation using the whole sample).

Overall, the two long-run path specification based on the split of the countries according to current account balance, external debt and inflation rates gives useful insights of the different dynamics across countries. ${ }^{13}$ For the analysis of the dynamics over time, we present both the results based on the same specification to all countries and those related to the two different groups.

\footnotetext{
${ }^{13}$ Appendix $3 b$ presents for each country the long-term path of government bond spreads based on the error correction specification (the grey triangle-line), along with the PMG model-based spreads (the grey circle-line) and actual spreads (the plain black line) according to the specifications of figures 3 and 4 .
} 


\subsection{Dynamics of fundamental-driven spreads}

The dynamics of the fundamentals-based government bond spreads takes into account the estimated coefficients on all fundamentals (in the short and the long-run as in Tables 1a-b or, alternatively, in Figures 3 and 4), country-specific constant terms as well as the persistence effects. Therefore, the fundamental-based spreads can be viewed as the level of spreads justified by macroeconomic indicators and past values.

Precisely, we can calculate the $A R D L(1,1, . ., 1)$ with the estimated parameters:

$$
\operatorname{Spr} \widetilde{e} a d s_{i t}=\widetilde{\mu}_{i}+\widetilde{\lambda}_{i} \operatorname{Spreads}_{i t-1}+\sum_{k=1}^{n-1} \widetilde{\delta}_{i 0}^{(k)} F_{i t}^{(k)}+\widetilde{\delta}_{i 1}^{(k)} F_{i t-1}^{(k)}
$$

where $F$ denotes the $(n-1)$ fundamental factors and parameters $\widetilde{\mu}_{i}, \tilde{\lambda}_{i}, \widetilde{\delta}_{i 0}^{(k)}$ and $\widetilde{\delta}_{i 1}^{(k)}$ are computed from the ECM estimates according to the formulas :

$$
\begin{gathered}
\widetilde{\mu}_{i}=-\widetilde{\alpha}_{i} \widetilde{\phi}_{i} \\
\widetilde{\lambda}_{i}=1+\widetilde{\phi}_{i} ; \\
\widetilde{\delta}_{i 0}^{(k)}=\frac{\widetilde{\beta}^{(k)}}{\widetilde{\phi}_{i}}-\widetilde{\delta}_{i 1}^{(k)}
\end{gathered}
$$

where $\widetilde{\phi}_{i}$ are the error-correction coefficients for each country, $\widetilde{\alpha}_{i}$ the country-specific intercepts, $\beta^{(k)}$ the long-run coefficients constant across countries and $\widetilde{\delta}_{i 1}^{(k)}$ the coefficients on the first differenced variables, in the short-run specification (see Tables 1a-b). The estimated spreads are presented on Charts 5a-h. The dotted line marks the beginning of the financial crisis in summer 2007.

As can be seen from the charts, the gap between actual and fundamental-driven spreads ${ }^{14}$ is relatively low for most countries, suggesting that fundamental factors and spreads persistence over time mostly account for the current spreads levels.

We use the evolution of fundamental-driven spreads to tackle two questions. First, we analyse more generally if actual spreads reflect well the evolution of countries' fundamentals and whether common factors play a role, as indications of potential contagion effects. Throughout the period under consideration, actual and fundamental-based spreads evolve closely in almost all countries with the exception of Romania and somewhat of Hungary and Slovakia, suggesting that fundamentals can explain most of government bond spreads fluctuations in those countries. As such, improved fundamentals and the prospect of EU accession has led to a compression of yield differentials relative to the euro area close or even below zero in some cases. Conversely, the financial turmoil seems to have enhanced the role of country-specific fundamentals in explaining spreads variations, even if the deterioration of fundamentals in some of those countries has started earlier than summer 2007. In Romania, and, to a lower extent in Hungary, actual spreads were higher than fundamental-based ones, with the gap between fundamental-driven and actual spreads suggesting a role for common identified or latent factors.

\footnotetext{
14 This gap normally reflects the impact of the common factor as well as other identified (liquidity, taxation) or latent (credibility) factors and spillover effects resumed in the PMG residuals.
} 
Charts 5a-h Evolution of fundamental-based and actual government bond spreads (in basis points)
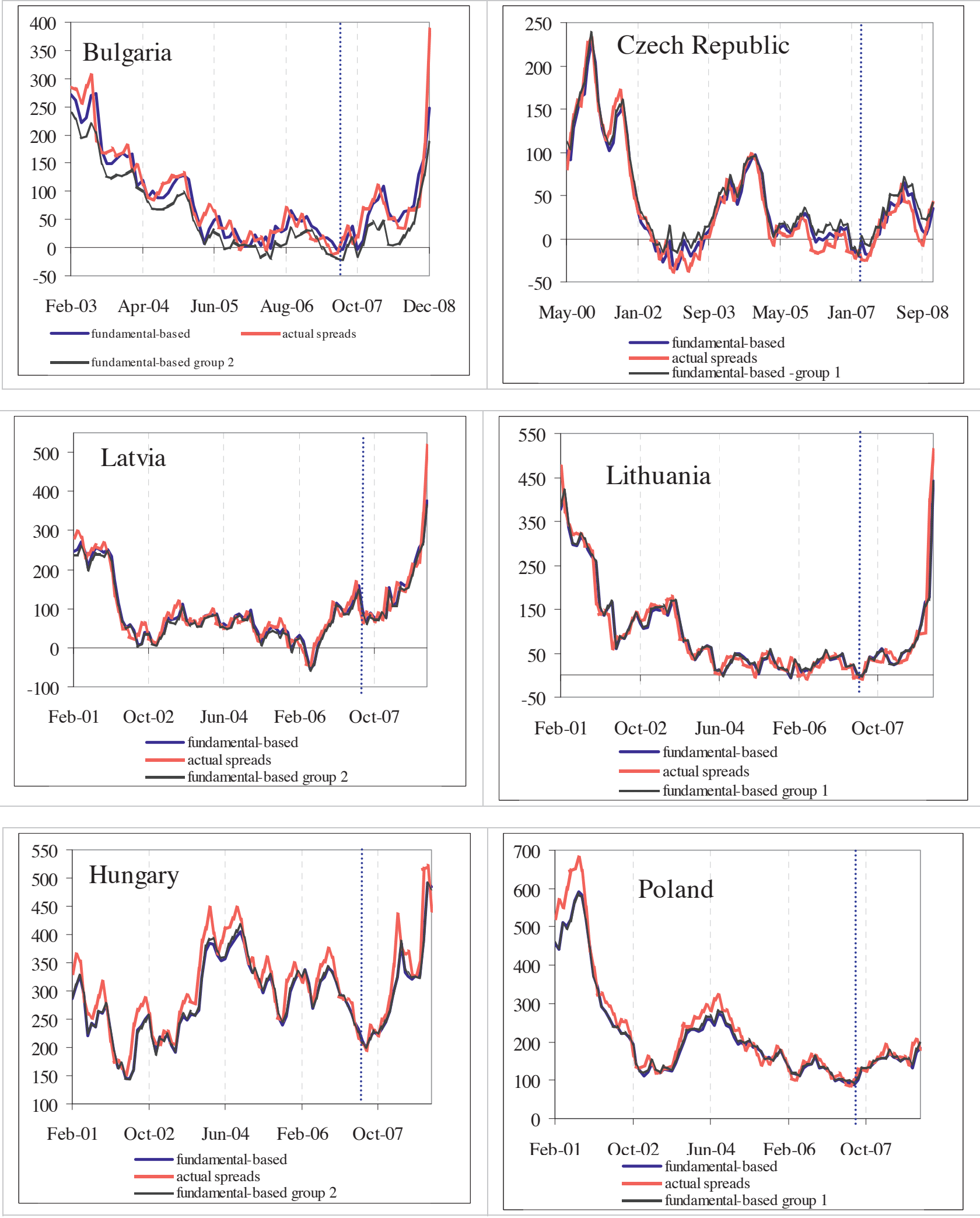


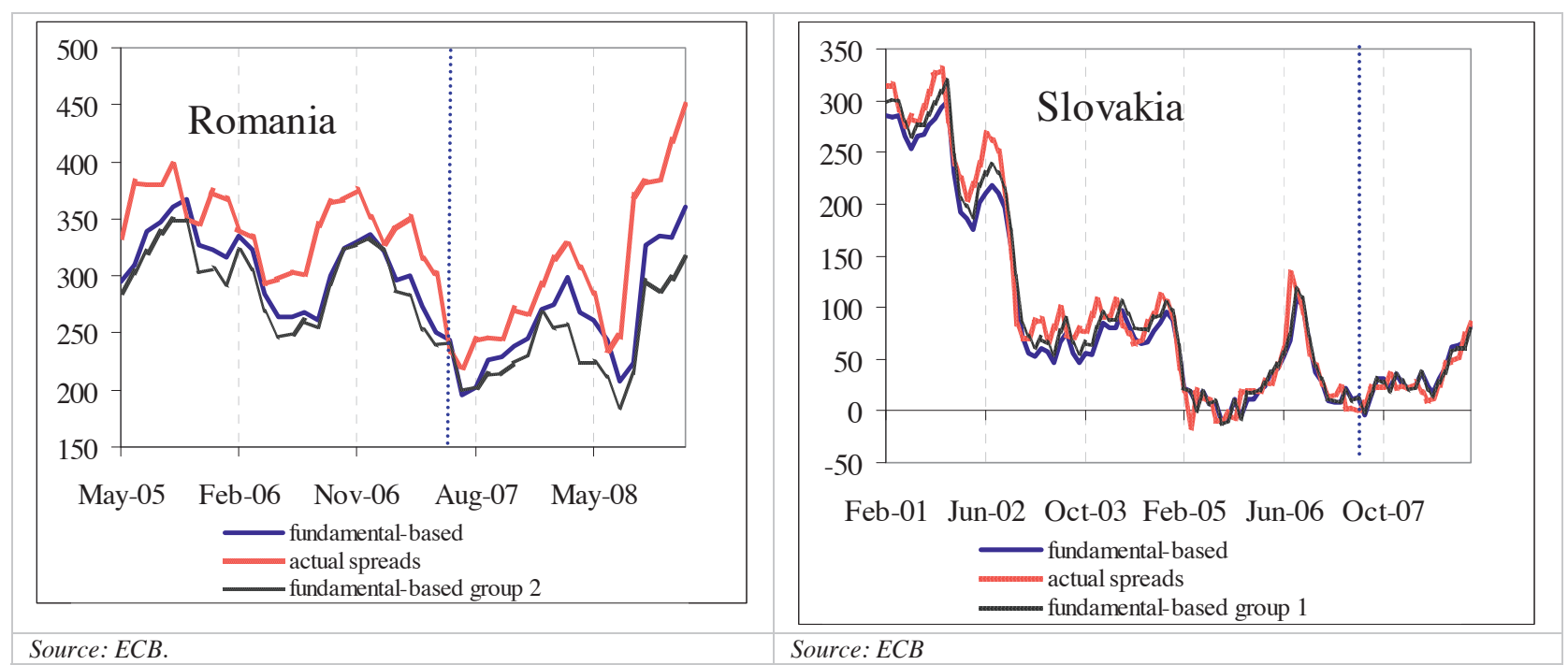

Note: The fundamental-based spreads refer to the spreads estimated according to relations (5) and (5.1). Last observation refers to December 2008.

Second, we look in particular at the recent period of market crisis which started in summer 2007 to analyse whether market perceptions of the creditworthiness of the new EU countries has somewhat shifted since then. Additionally, we want to investigate whether the recent surge in government bond spreads is driven by common factors, by domestic sources of vulnerability or by a combination of the two. Even if for some of the new EU countries and in particular for Latvia, spreads started to rise before the beginning of the crisis, for most of the other countries the crisis marks the beginning of an upward trend, where fundamentals have a major role to play. The increase in spreads has been mainly driven by fundamentals, but from relatively low levels (below 50 b.p.), in the Czech Republic and Slovakia, most of the countries of the first sub-group, characterised by a positive current account balance. In these countries, actual spreads are lower than fundamental-driven ones, suggesting that the common and unexplained factors exerted a downward pressure on spreads. For Bulgaria this has also been the case until September 2008 where spreads started to rise reaching historical heights by the end of the year.

In Hungary, both fundamentals and common factors contributions are positive and explain spreads variation over the period 2005 to end-2008. This suggests that the unfavourable contribution stemming from country-specific developments added to the adverse impact of worsening global financial conditions in explaining recent high government bond spreads. For instance, at the second peak of Hungarian government bond spreads, of 521 b.p. in November 2008, the combined impact of fundamentals and persistence explains more than $90 \%$ of that spread. A similar configuration is found for Romania where the unexplained part of spreads over the recent period adds to the negative impact of deteriorating fundamentals to further widen government bond spreads. For instance, at the peak of 450 b.p reached in December 2008, fundamentals explain almost 360 b.p. of spreads level, the remaining gap being attributed to common factors and spillover effects. Contrary to Hungary and Romania, the importance of common and unexplained factors faded away at the turning of 2008 in Bulgaria and Latvia, where spreads seem to be driven essentially by fundamental factors.

Overall, it is noticeable that common and unexplained factors are likely to play a bigger role for Bulgaria, Hungary and Romania, thus rendering them more exposed to spillover effects, while for the other countries, the evolutions in spreads seem mainly driven by fundamentals.

\section{An application of the model}

From an historical perspective, favourable global financial conditions from roughly mid-2003 to mid-2007, as well as the process of structural economic and financial integration of the new EU countries, brought about high rates of economic growth and financial deepening. At the same time, massive capital inflows into these economies have stirred the risk of overheating and financial imbalances, thereby increasing their vulnerability to a sudden reversal in capital flows. In order to assess the likely impact of a deterioration of some fundamentals on government bond spreads, we use the results of our main model presented up to now to 
compute the impact of different country-specific and common shocks. The spreads reaction will be different across countries depending on spreads elasticities to changes in fundamental and common factors, in the long and the short-run.

For instance, at levels of government bond spreads of December 2008, a one standard deviation increase in external debt over GDP ratio puts upward pressures on spreads in Hungary (a rise by 12 b.p. is expected according to our estimates), Bulgaria (4.5 b.p) and to a lower extent in Czech Republic (3 b.p) and Slovakia (1.3 b.p.) (see Appendix 1). A highest impact is recorded for the interest payments on government debt over GDP ratio: an increase by one standard deviation affects sovereign spreads in Slovakia (391 b.p. increase in spreads), Latvia (142 b.p), Poland (184 b.p) and to a lower extent Hungary (17.25 b.p.). A one standard deviation decline in the fiscal balance-to-GDP ratio is likely to drive government bond spreads upward in Slovakia by 7 b.p. and most notably in Hungary, by 29 b.p. A similar adverse shock to the current account position would affect spreads in Latvia (13 b.p. increase), Czech republic (3.2 b.p. increase) and to a lower extent Lithuania (1.73 b.p. increase).A one standard deviation increase in inflation would particularly affect spreads in Poland (31 b.p. increase), Slovakia and Hungary (14 b.p), Czech Republic (9 b.p) and Romania (6 b.p). The worsening of conditions in the money market, as reflected by an one standard deviation in short term spreads (in basis points) is likely to affect long-term spreads in all countries, to different degrees: from around 130 b.p. increase in Romania and Poland, to 40 b.p. in Hungary and 29 in Bulgaria, 20 b.p. in Czech Republic and Latvia and 14 b.p. in Lithuania. Finally, if we consider a one standard deviation increase in the euro area equity volatility, most affected would be Hungary (increase by 19 b.p), Poland (12 b.p), Czech Republic and Slovakia (3 b.p) whereas in the other countries the impact would be negligible.

\subsection{Robustness checks}

\section{Portmanteau test for white noise}

Table 2 reports the results of the (portmanteau) Q-test for serial independence of the PMG model residuals performed up to 30 lags. For all countries, the null hypothesis of no serial correlation up to 30th order in the disturbance process is accepted, suggesting that the residual series from the main explanatory model of spreads are serial independent.

Table 2: Test for PMG residual autocorrelation

\begin{tabular}{|l|c|c|c|}
\hline & no obs. & Q-Stat & $\begin{array}{c}\text { Prob > } \\
\text { chi2(30) }\end{array}$ \\
\hline Bulgaria & 71 & 18.85 & 0.94 \\
\hline Czech Republic & 104 & 21.83 & 0.85 \\
\hline Latvia & 89 & 27.04 & 0.62 \\
\hline Lithuania & 89 & 16.89 & 0.97 \\
\hline Hungary & 89 & 16.52 & 0.97 \\
\hline Poland & 91 & 35.52 & 0.22 \\
\hline Romania & 40 & 30.76 & 0.42 \\
\hline Slovakia & 89 & 27.77 & 0.58 \\
\hline
\end{tabular}

\section{Exogenous separation of the panel: inflation-target versus exchange-rate target countries}

As an additional robustness check of our results based on the PMG methodology we look at the performance of our model on two exogenously identified groups of countries, according to their monetary arrangement i.e. either targeting the inflation rate (CEEC-IT) or the exchange rate (CEEC-FX) $)^{15}$.

The countries in our sample can be exogenously classified according to their monetary arrangement: half of them are targeting the inflation rate thereby letting their exchange rate floating as they are not yet member of the ERM II system (Czech Republic, Poland, Hungary and Romania). The other half (Bulgaria, Latvia, Lithuania and Slovakia) target the exchange rate either under the form of a hard peg (Bulgaria) or as part of ERM II after years of a currency board (Lithuania since June 2004 and Latvia, since May 2005) or as a new commitment at the end of a period of managed floating exchange rate (Slovakia since 2005). The results of the long-run determinants and country error correction coefficients, for each group, are reported in Tables $3 a-b$.

\footnotetext{
${ }^{15}$ For the exchange rate targeters, the exchange rate was excluded from the short-run specification.
} 
Tables 3a-b: Long-run determinants and error correction terms

5.2.a CEEC-IT countries

\begin{tabular}{|l|r|}
\hline ExtDebt & $4.79^{* *}$ \\
\hline $\begin{array}{l}\text { Fiscal } \\
\text { Balance }\end{array}$ & -9.52 \\
\hline Trade0p & $-2.55^{* *}$ \\
\hline Inflation & $27.47^{* * *}$ \\
\hline Exch. rate & 0.22 \\
\hline $\begin{array}{l}\text { Short } \\
\text { i.r.spread }\end{array}$ & $0.36^{* * *}$ \\
\hline $\begin{array}{l}\text { EAequity } \\
\text { vola }\end{array}$ & $-1.94^{* *}$ \\
\hline
\end{tabular}

\begin{tabular}{|l|l|}
\hline & $\begin{array}{l}\text { Error } \\
\text { correction }\end{array}$ \\
\hline Czech Rep. & $-0.18^{* * *}$ \\
\hline Hungary & $-0.09^{* * *}$ \\
\hline Poland & $-0.17^{* * *}$ \\
\hline Romania & $-0.13^{* * *}$ \\
\hline
\end{tabular}

*** indicates significance at $1 \%, * *$ indicates significance at $5 \%$ and $*$ indicates significance at $10 \%$ 5.2.b CEEC-FX countries

\begin{tabular}{|c|c|c|c|}
\hline \multicolumn{4}{|c|}{ 5.2.b CEEC-FX countries } \\
\hline ExtDebt & $4.88^{* *}$ & & $\begin{array}{l}\text { Error } \\
\text { correction }\end{array}$ \\
\hline $\begin{array}{l}\text { Fiscal } \\
\text { Balance }\end{array}$ & -3.80 & Bulgaria & $-0.08^{* * *}$ \\
\hline TradeOp & -1.59 & Latvia & $-0.05^{* *}$ \\
\hline Inflation & $14.13^{* *}$ & $\begin{array}{l}\text { Lithuani } \\
\mathrm{a}\end{array}$ & $-1.10^{* * *}$ \\
\hline Exch. rate & -3.01 & Slovakia & $0.17^{* *}$ \\
\hline $\begin{array}{l}\text { Short } \\
\text { i.r.spread }\end{array}$ & $0.41^{* * *}$ & & \\
\hline $\begin{array}{l}\text { EAequity } \\
\text { vola }\end{array}$ & 0.04 & & \\
\hline
\end{tabular}

The results show that the model fits well the first group of inflation targeters. Moreover, the long-run sensitivities of government bond spreads to changes in the level of inflation, trade openness, short-term spreads and euro area equity volatility are higher than those computed on the whole sample of new EU countries. As far as the second group is concerned, the long-run relationship appears to be less strong ${ }^{16}$. Even if most signs of variables are coherent with the results for the whole sample, only the external debt-to-GDP, inflation and the short-term interest rate spreads are significant in the long-run.

\section{Policy implications and conclusions}

Among the Maastricht convergence criteria used for assessing the countries, which are in the process of entering into the euro-zone, the long-term interest rate is a measure of the durability and sustainability of a country's convergence process, or, put it differently, a reflection of the financial market assessment of the economic fundamentals' sustainability, particularly with a view to the stability of the fiscal balance and risk premia. In the regular analysis carried out by the Eurosystem, the assessment is based on the convergence of ten-year government bond yields to the euro area average.

Against this background, we proposed an empirical investigation into the main determinants of government bond spreads in the new EU countries taking into account some specific features that distinguish these countries from other emerging economies. These are a persistence of short-run heterogeneities, and an adjustment trend to equilibrium values over medium to long-run, as part of the convergence process. Moreover, we assess spreads developments on the basis of the convergence criteria set by the Maastricht Treaty (public debt, fiscal deficit, inflation), making it easier to select potential fundamentals that may influence market perception of countries' creditworthiness.

In order to deal with these specificities, we adopted a dynamic panel approach based on the pooled mean group technique first proposed by Pesaran, Shin and Smith (1999). This is basically an error-correction model allowing for both long-run homogeneity and short-run differences in coefficients and error variances across countries. The results of the PMG estimation on the initial sample of eight new EU countries showed that external debt-to-GDP, inflation and exchange rates, countries' openness to trade, short-term interest rates differentials with the corresponding euro area rates as well as the equity market volatility in the euro area are the main long-run determinants of spreads. We then used the estimated coefficients to derive a fundamental-based measure of spreads, where the gap from actual ones reflects common factors and spillover effects not explicitly taken into account in the econometric specification.

The evolution of the actual and fitted series of spreads puts into light that countries' fundamentals are important determinants of financial conditions in the new EU countries. They explain the major part of spreads variations in countries like Czech Republic, Latvia, Lithuania, Bulgaria and Poland.

\footnotetext{
${ }^{16}$ Removing Slovakia, not a former currency board country, does not change the significance of the long-run specification.
} 
We also put into light that there may be two clusters among the new EU countries that evolve in different long-run paths, thus showing different elasticities in the long-run to fundamentals and common factors characterising the euro area. A joint criterion based on current account balance-to-GDP, external debt and inflation rates offers the best split of the sample into one group displaying relatively better fundamentals (Czech Republic, Lithuania, Poland and Slovakia) and a second group characterised by generally higher external vulnerability (Bulgaria, Latvia, Hungary and Romania) throughout the period.

As regards the recent period of market turmoil starting in summer 2007, our estimated results suggested that the rise in spreads in countries like Hungary and Romania is driven by a mix of deteriorating fundamentals and increased dependence upon external conditions. In Bulgaria, Latvia and Lithuania, fundamentals have become prevalent in 2008 and their recent abrupt deterioration has immediately translated into higher risk premia required by investors to hold government debt securities. For other countries in the sample -the Czech Republic and Slovakia- we noticed that fundamental-driven spreads are, at times, slightly higher than actual ones. This feature suggests increased investors' differentiation in a context of heightened uncertainty and risk aversion. At the same time, these countries are characterised by relatively better current account position than the rest of the sample, which brings us to the idea that common factors may affect new EU countries differently, based on the quality of their fundamentals. . In the case of Poland, our estimates do not show changes in the pattern of government bond spreads with fundamentals mostly explaining actual spreads. 


\section{References}

Afonso A., P. Gomes and P. Rother (2007) "What "Hides" Behind Sovereign Debt Ratings?", ECB Working Paper Series No. 171. Akitoby B. and T. Stratman (2008) "Fiscal policy and Financial Markets”, Economic Journal, 118(533), pp.1971-85

Baldacci, E., Gupta, S. and A. Mati (2008) "Is it (Still) Mostly Fiscal? Determinants of Sovereign Spreads in Emerging Markets", IMF Working Paper no 08/259, November.

Baltagi, B.H. and J.M. Griffin (1997) "Pooled estimators vs. their heterogeneous counterparts in the context of dynamic demand for gasoline", Journal of Econometrics, 77, pp. 303-327.

Beber, A., Brandt, M.W. and K.A. Kavajecz (2008) "Flight-to-Quality or Flight-to-Liquidity? Evidence from the Euro-Area Bond Market", The Review of Financial Studies, forthcoming.

Bernoth K., J.V. Hagen and L. Schuknecht (2006), “Sovereign Risk Premiums in the European Government Bond Market”, SFB/TR 15 Discussion Papers 151.

Boyd, D and R. Smith (2002) "Some Econometric issues in measuring the Transmission Mechanism, with an application to Developing Countries", in Monetary Transmission in Diverse Economies, (eds.) L. Mahadeva and P. Sinclair, Cambridge University Press, 2002.

Bunda, I., Hamann, A.J. and S. Lall (2009) "Correlations in emerging market bonds: The role of local and global factors", Emerging Markets Review, 10(2), pp. 67-96.

Ciarlone, A., Piselli, P. and G. Trebeschi (2007) “Emerging Markets Spreads and Global Financial Conditions”, Bank of Italy Temi di Discussione No. 637, June.

Codogno, L., Missale, A. and C. Favero (2003) "Yield Spreads on EMU Government Bonds”, Economic Policy, Vol. 18, No. 37, p. 503, October.

Edwards, S., 1984, "LDC Foreign Borrowing and Default Risk: an Empirical Investigation, 1976-80”, American Economic Review, Vol. 74, N. 4, 726-34.

Eichengreen B., Rose, A.K. and C. Wyplosz (1995) "Exchange market mayhem: The antecedents and aftermath of speculative attacks”, Economic Policy, Vol. 21 (October), pp. 249-312.

Favero, C.A., F. Giavazzi and L. Spaventa (1997), 'High yields: the spread on German interest rates', The Economic Journal, 107, pp. 956-85.

Favero, C., Pagano, M. and E.L. von Thadden (2005) Valuation, Liquidity and Risk in Government Bond Markets, IGIER Università Bocconi Working Paper no. 281, January.

Ferrucci, G. (2003) "Empirical determinants of emerging market economies' sovereign bond spreads", Bank of England Working Paper no. 205.

Geyer, A., Kossmeier, S. and S. Pichler (2004) "Measuring Systematic Risk in EMU Government Yield Spreads?", Review of Finance 8: 171-197.

Goyenko, R., Subrahmanyam, A. and A. Ukhov (2008) “The Term Structure of Bond Market Liquidity”, EFA 2008 Athens Meetings Paper.

Haque, N.U., Pesaran, M. H and S. Sharma, "Neglected Heterogeneity and Dynamics in cross-country Savings Regressions", in (eds) J. Krishnakumar and E. Ronchetti, Panel Data Econometrics - Future Direction: Papers in Honour of Professor Pietro Balestra, in the series, "Contributions to Economic Analysis", Elsevier Science, 2000, chapter 3, pp.53-82.

Koukouritakis, M. and L. Michelis (2008) "The term structure of interest rates in the 12 newest EU countries", Applied Economics, Vol. 40:4, pp. 479-490. 
Lonning, I. (2000), "Default Premia on European Government Debt", Weltwirtschaftliches-Archiv/Review-of-World-Economics, 136(2), pp. 259-83.

Manganelli, S. and G. Wolswijk (2009), “What drives spreads in the euro area government bond market?”, Economic Policy, 48: 191-240.

Mihaljek, D. and M. Klau (2008) "Catching-up and inflation in transition economies: the Balassa-Samuelson effect revisited", BIS Working paper no 270, December.

Min, H.G. (1998) "Determinants of Emerging Market Bond Spread: Do Economic Fundamentals Matter?", World Bank Policy Research Working Paper No. 1899.

Pagano, M. and E.L. von Thadden (2004) "The European Bond Markets under EMU”, Oxford Review of Economic Policy, Vol. 20(4), pp. 531-554.

Pesaran, M. H, Shin, Y. and R.P. Smith (1999), "Pooled mean group estimation of dynamic heterogeneous panels", Journal of the American Statistical Association, Vol.94, pp.621-634.

Pesaran, M. H and Y. Shin (1999), "An autoregressive distributed lag modelling approach to cointegration analysis", in (ed.) S. Strom, Econometrics and Economic Theory in the 20th Century: The Ragnar Frisch Centennial Symposium, chapter 11, Cambridge University Press.

Schuknecht, L., von Hagen, J. and G. Wolswijk (2008), "Government risk premiums in the bond market EMU and Canada", ECB Working Paper Series no. 879, March.

K. Strahilov (2006), "The determinants of country risk in Eastern European countries. Evidence from sovereign bond spreads", Bruges European Economic Research Papers No. 8. 


\section{Appendix 1: Definition of variables, descriptive statistics and unit root tests}

New EU countries long-term government bond spreads: monthly averages computed from yields on long-term government bonds or closest available maturity used for convergence purposes relative to the long-term euro area average yield provided by the ECB, for the following new EU countries: Bulgaria (from Jan-03, 72 observations available), Czech Republic (from April-00, 105 observations available), Hungary, Latvia, Lithuania, Poland and Slovakia (from Jan-01, 96 observations available), Romania (from April-05, 45 observations available). Data are available on http://www.ecb.europa.eu/stats/money/long/html/index.en.html

Euro area long-term government bond yield: weighted average of harmonised national ten-year benchmark government bond yields (as reported by Reuters), where the country weights are calculated on the basis of nominal outstanding amounts of government bonds in the ten-year maturity band. Data are available on http://www.ecb.europa.eu/stats/money/long/html/index.en.html

Gross government debt-to-GDP ratio: monthly linearly interpolated from annual general government consolidated gross debt in accordance with the excessive deficit procedure in percentage of GDP, at market prices, provided by Eurostat.

Interest payments on public debt-to-GDP ratio: monthly linearly interpolated from annual general government interest payments on government debt-to-GDP ratio, at market prices, provided by Eurostat.

Fiscal balance-to-GDP ratio: monthly linearly interpolated from quarterly values of the general government net lending $(+)$ or net borrowing (-) data according to the excessive deficit procedure, in percentage of GDP at market prices, provided by Eurostat.

Current account balance-to-GDP ratio: monthly interpolated from quarterly ratios computed from current account and GDP series in domestic currency, provided by Eurostat.

Gross external debt-to-GDP ratio: monthly linearly interpolated from quarterly ratios computed from gross external debt and GDP in domestic currency, provided by Eurostat.

Inflation rates: monthly HICP provided by ECB.

Ln (income per capita): monthly interpolated from annual gross national income per capita (in logarithm) computed from gross national income at market prices and population figures provided by Eurostat.

Exchange rates: computed as indices $(\mathrm{Jan}-2000=100)$ on the basis of spot rates of domestic currencies against the euro, monthly averages provided by ECB and National Central Banks.

Trade openness: monthly interpolated from quarterly ratios of total volume of imports and exports-to-GDP based on imports, exports and GDP series in national currency, provided by Eurostat.

Short-term spreads: computed as the monthly differential of the average 3-month money market interest rates (deposit rates) denominated in domestic currency and the 3-month EURIBOR, provided by Reuters.

Euro Area stock market volatility: monthly averages of implied stock market volatility for the Dow Jones Eurostoxx 50 index provided by Bloomberg. 
Descriptive statistics and pair wise correlations

\begin{tabular}{|c|c|c|c|c|c|c|c|c|c|c|c|c|}
\hline All countries & Spreads & ExtDebt & GGvDebt & int.paym. & Income & CA & Inflation & Fbalance & TradeOp & $\begin{array}{l}\text { Exch. } \\
\text { rate }\end{array}$ & $\begin{array}{l}\text { Short } \\
\text { i.r.spread }\end{array}$ & $\begin{array}{l}\text { EAequity } \\
\text { volat }\end{array}$ \\
\hline Spreads & & & & & & & & & & & & \\
\hline ExtDebt & 0.05 & & & & & & & & & & & \\
\hline GGvDebt & $0.39 *$ & -0.04 & & & & & & & & & & \\
\hline int.paym. & $0.54^{*}$ & -0.00 & $0.93^{*}$ & & & & & & & & & \\
\hline Income & $0.25^{*}$ & $-0.11^{*}$ & $0.58^{*}$ & $0.53^{*}$ & & & & & & & & \\
\hline CA & $0.15^{*}$ & $-0.45^{*}$ & $0.37^{*}$ & $0.30 *$ & $0.20^{*}$ & & & & & & & \\
\hline Inflation & $0.15^{*}$ & $0.60^{*}$ & $-0.12 *$ & -0.01 & -0.06 & $-0.41^{*}$ & & & & & & \\
\hline Fbalance & $-0.36^{*}$ & $0.28^{*}$ & $-0.61 *$ & $-0.63^{*}$ & $-0.55^{*}$ & $-0.38^{*}$ & $0.27^{*}$ & & & & & \\
\hline TradeOp & $-0.35^{*}$ & $0.16^{*}$ & $0.22^{*}$ & $0.13^{*}$ & $0.28^{*}$ & $-0.10^{*}$ & $0.16^{*}$ & -0.02 & & & & \\
\hline Exch. rate & $0.40^{*}$ & $0.10^{*}$ & $-0.26^{*}$ & $-0.13^{*}$ & $-0.17^{*}$ & $-0.22^{*}$ & $0.33^{*}$ & $0.11^{*}$ & $-0.41^{*}$ & & & \\
\hline Short i.r.spread & $0.81^{*}$ & $0.13^{*}$ & $0.34^{*}$ & $0.54^{*}$ & $0.19^{*}$ & 0.03 & $0.31^{*}$ & $-0.32 *$ & $-0.33^{*}$ & $0.39 *$ & & \\
\hline EAequity volat & $0.15^{*}$ & -0.01 & 0.01 & 0.08 & 0.01 & 0.03 & -0.08 & $-0.15^{*}$ & $-0.11^{*}$ & -0.07 & $0.15^{*}$ & \\
\hline obs & 702 & 702 & 702 & 702 & 702 & 702 & 702 & 702 & 702 & 702 & 702 & 702 \\
\hline Mean & 150.22 & 57.12 & 32.12 & 1.91 & 9.07 & -8.80 & 4.77 & -2.88 & 121.11 & 100.84 & 238.94 & 22.78 \\
\hline Std.Dev. & 137.45 & 21.60 & 16.03 & 1.25 & 2.07 & 7.09 & 3.36 & 3.03 & 30.66 & 25.76 & 268.11 & 10.50 \\
\hline $\operatorname{Min}$ & -46.03 & 30.28 & 9.54 & 0.48 & 6.21 & -39.06 & -1.87 & -11.90 & 55.48 & 65.35 & -137.53 & 10.78 \\
\hline $\operatorname{Max}$ & 680.18 & 128.16 & 65.81 & 5.30 & 13.36 & 12.71 & 17.70 & 7.39 & 184.11 & 210.99 & 1418.56 & 56.66 \\
\hline
\end{tabular}

\begin{tabular}{|c|c|c|c|c|c|c|c|c|c|c|c|c|}
\hline Bulgaria & Spreads & ExtDebt & GGvDebt & int.paym. & Income & CA & Inflation & Fbalance & Trade0p & Exch. rate & $\begin{array}{l}\text { Short } \\
\text { i.r.spread }\end{array}$ & $\begin{array}{l}\text { EAequity } \\
\text { volat }\end{array}$ \\
\hline \multicolumn{13}{|l|}{ Spreads } \\
\hline ExtDebt & -0.18 & & & & & & & & & & & \\
\hline GGvDebt & $0.60^{*}$ & $-0.83^{*}$ & & & & & & & & & & \\
\hline int.paym. & $0.47^{*}$ & $-0.91^{*}$ & $0.97^{*}$ & & & & & & & & & \\
\hline Income & $-0.41^{*}$ & $0.91^{*}$ & $-0.91^{*}$ & $-0.93^{*}$ & & & & & & & & \\
\hline CA & $0.32^{*}$ & $-0.57 *$ & $0.66^{*}$ & $0.65^{*}$ & $-0.56^{*}$ & & & & & & & \\
\hline Inflation & $-0.50^{*}$ & $0.70^{*}$ & $-0.75^{*}$ & $-0.78^{*}$ & $0.75^{*}$ & $-0.45^{*}$ & & & & & & \\
\hline Fbalance & $-0.43^{*}$ & $0.49^{*}$ & $-0.69^{*}$ & $-0.63^{*}$ & $0.58^{*}$ & $-0.43^{*}$ & 0.21 & & & & & \\
\hline TradeOp & $-0.75^{*}$ & $0.50^{*}$ & $-0.79 *$ & $-0.72^{*}$ & $0.56^{*}$ & $-0.42^{*}$ & $0.62^{*}$ & $0.52^{*}$ & & & & \\
\hline Exch. rate & $-0.54^{*}$ & $0.39^{*}$ & $-0.65^{*}$ & $-0.57^{*}$ & $0.57^{*}$ & $-0.38^{*}$ & $0.46^{*}$ & $0.47^{*}$ & $0.52^{*}$ & & & \\
\hline $\begin{array}{l}\text { Short } \\
\text { jirspread }\end{array}$ & & & & & & & & & & & & \\
\hline $\begin{array}{l}\text { i.r.spread } \\
\text { EAequity }\end{array}$ & $0.39^{*}$ & $0.32^{*}$ & -0.06 & -0.189 & 0.20 & -0.03 & $0.30^{*}$ & -0.21 & -0.25 & -0.22 & & \\
\hline volat & $0.61^{*}$ & $0.39^{*}$ & 0.01 & -0.11 & 0.11 & -0.09 & -0.02 & -0.04 & -0.26 & -0.21 & $0.39^{*}$ & \\
\hline obs & 72 & 72 & 72 & 72 & 72 & 72 & 72 & 72 & 72 & 72 & 72 & 72 \\
\hline Mean & 91.50 & 72.95 & 30.99 & 1.58 & 7.31 & -15.77 & 6.93 & 2.09 & 137.14 & 99.92 & 135.82 & 20.74 \\
\hline Std.Dev. & 87.22 & 15.28 & 12.02 & 0.42 & 0.24 & 11.95 & 3.45 & 1.88 & 14.76 & 0.17 & 81.96 & 9.73 \\
\hline Min & -11.31 & 54.94 & 13.76 & 0.87 & 6.83 & -39.06 & -0.16 & -0.58 & 107.34 & 99.51 & -10.33 & 10.78 \\
\hline Max & 387.00 & 109.67 & 52.99 & 2.26 & 7.78 & 12.71 & 14.73 & 7.39 & 161.71 & 100.02 & 444.74 & 56.66 \\
\hline
\end{tabular}

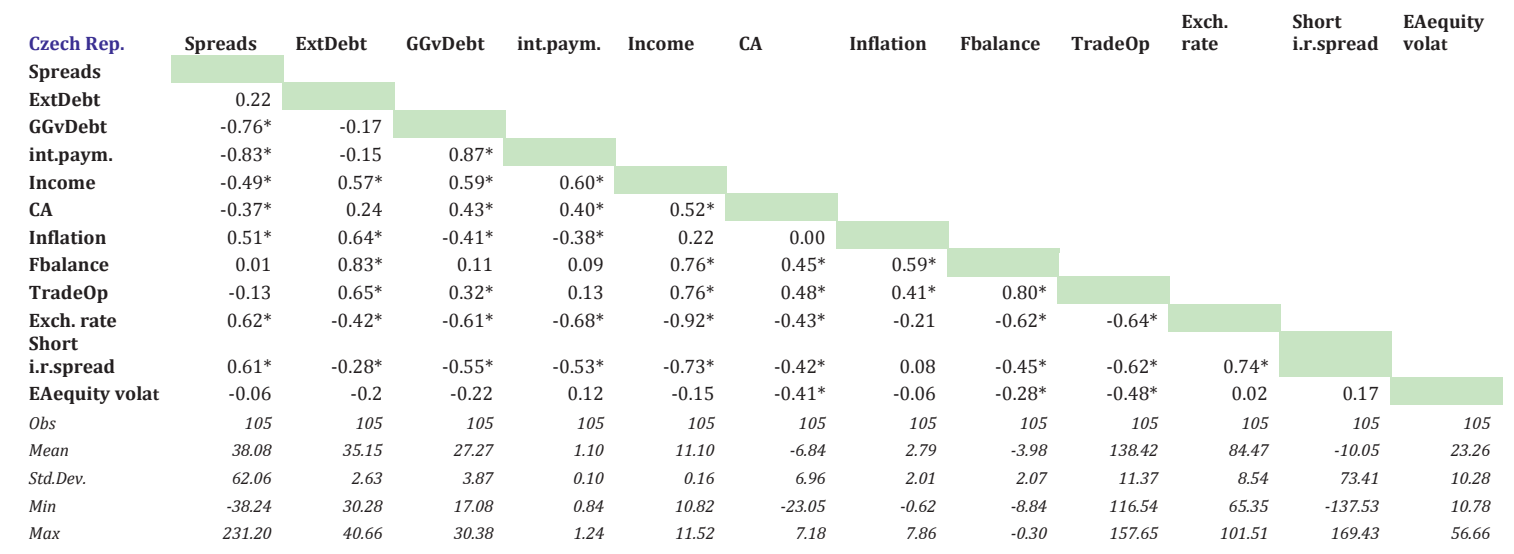

\begin{tabular}{|c|c|c|c|c|c|c|c|c|c|c|c|c|}
\hline Latvia & Spreads & ExtDebt & GGvDebt & int.paym. & Income & CA & Inflation & Fbalance & Trade0p & Exch. rate & $\begin{array}{l}\text { Short } \\
\text { i.r.spread }\end{array}$ & $\begin{array}{l}\text { EAequity } \\
\text { volat }\end{array}$ \\
\hline \multicolumn{13}{|l|}{ Spreads } \\
\hline ExtDebt & 0.05 & & & & & & & & & & & \\
\hline GGvDebt & -0.11 & $-0.73^{*}$ & & & & & & & & & & \\
\hline int.paym. & 0.26 & $-0.89^{*}$ & $0.69 *$ & & & & & & & & & \\
\hline Income & 0.02 & $0.98^{*}$ & $-0.78^{*}$ & $-0.92 *$ & & & & & & & & \\
\hline CA & 0.25 & $-0.68^{*}$ & $0.69 *$ & $0.78^{*}$ & $-0.72^{*}$ & & & & & & & \\
\hline Inflation & 0.11 & $0.90^{*}$ & $-0.64^{*}$ & $-0.75^{*}$ & $0.89^{*}$ & $-0.51^{*}$ & & & & & & \\
\hline Fbalance & $-0.42^{*}$ & $0.61^{*}$ & $-0.53^{*}$ & $-0.78^{*}$ & $0.67^{*}$ & $-0.75^{*}$ & $0.47^{*}$ & & & & & \\
\hline TradeOp & $-0.43^{*}$ & $0.55^{*}$ & $-0.47^{*}$ & $-0.73^{*}$ & $0.61^{*}$ & $-0.77^{*}$ & $0.49^{*}$ & $0.82^{*}$ & & & & \\
\hline Exch. rate & $-0.27^{*}$ & $0.82^{*}$ & $-0.47^{*}$ & $-0.92 *$ & $0.84^{*}$ & $-0.67^{*}$ & $0.70^{*}$ & $0.78^{*}$ & $0.79 *$ & & & \\
\hline $\begin{array}{l}\text { Short } \\
\text { i.r.spread }\end{array}$ & $0.51^{*}$ & $0.40^{*}$ & $-0.34^{*}$ & -0.22 & $0.39 *$ & -0.20 & $0.35 *$ & 0.13 & -0.10 & 0.15 & & \\
\hline EAequity volat & $0.32^{*}$ & -0.16 & 0.09 & 0.24 & -0.18 & $0.42^{*}$ & -0.19 & $-0.50^{*}$ & $-0.63^{*}$ & $-0.39^{*}$ & 0.19 & \\
\hline obs & 96 & 96 & 96 & 96 & 96 & 96 & 96 & 96 & 96 & 96 & 96 & 96 \\
\hline Mean & 102.78 & 88.04 & 12.73 & 0.67 & 6.82 & -13.04 & 6.56 & -0.96 & 102.22 & 110.25 & 214.87 & 23.24 \\
\hline Std.Dev. & 91.32 & 21.37 & 1.65 & 0.15 & 0.41 & 6.51 & 4.43 & 1.07 & 8.44 & 9.12 & 182.15 & 10.72 \\
\hline Min & -46.03 & 56.51 & 9.54 & 0.48 & 6.21 & -27.23 & 0.67 & -2.75 & 88.54 & 91.11 & 6.81 & 10.78 \\
\hline $\operatorname{Max}$ & 514.00 & 128.16 & 14.94 & 0.97 & 7.52 & -2.21 & 17.70 & 0.82 & 119.99 & 119.35 & 1064.74 & 56.66 \\
\hline
\end{tabular}




\begin{tabular}{|c|c|c|c|c|c|c|c|c|c|c|c|c|}
\hline Lithuania & Spreads & ExtDebt & GGvDebt & int.paym. & Income & CA & Inflation & Fbalance & Trade0p & $\begin{array}{l}\text { Exch. } \\
\text { rate }\end{array}$ & $\begin{array}{l}\text { Short } \\
\text { i.r.spread }\end{array}$ & $\begin{array}{l}\text { EAequity } \\
\text { volat }\end{array}$ \\
\hline \multicolumn{13}{|l|}{ Spreads } \\
\hline ExtDebt & -0.14 & & & & & & & & & & & \\
\hline GGvDebt & $0.56^{*}$ & $-0.80^{*}$ & & & & & & & & & & \\
\hline int.paym. & $0.61^{*}$ & $-0.74^{*}$ & $0.99 *$ & & & & & & & & & \\
\hline Income & $-0.38^{*}$ & $0.92^{*}$ & $-0.94^{*}$ & $-0.92^{*}$ & & & & & & & & \\
\hline CA & $0.42^{*}$ & $-0.45^{*}$ & $0.51^{*}$ & $0.49^{*}$ & $-0.46^{*}$ & & & & & & & \\
\hline Inflation & -0.16 & $0.92^{*}$ & $-0.74^{*}$ & $-0.69^{*}$ & $0.84^{*}$ & $-0.40^{*}$ & & & & & & \\
\hline Fbalance & $-0.70^{*}$ & $0.28^{*}$ & $-0.72^{*}$ & $-0.77^{*}$ & $0.54^{*}$ & $-0.38^{*}$ & 0.18 & & & & & \\
\hline Trade0p & $-0.55^{*}$ & $0.65^{*}$ & $-0.82^{*}$ & $-0.83^{*}$ & $0.76^{*}$ & $-0.46^{*}$ & $0.67^{*}$ & $0.67^{*}$ & & & & \\
\hline Exch. rate & $0.63^{*}$ & -0.17 & $0.47^{*}$ & $0.54^{*}$ & $-0.39^{*}$ & 0.206 & -0.15 & $-0.53^{*}$ & $-0.42^{*}$ & & & \\
\hline $\begin{array}{l}\text { Short } \\
\text { i.r.spread }\end{array}$ & $0.74^{*}$ & 0.24 & 0.11 & 0.18 & 0.04 & 0.15 & 0.18 & $-0.32^{*}$ & $-0.45^{*}$ & $0.39 *$ & & \\
\hline EAequity volat & $0.49^{*}$ & -0.00 & $0.36^{*}$ & $0.34^{*}$ & -0.16 & $0.27^{*}$ & -0.08 & $-0.45^{*}$ & -0.26 & 0.12 & $0.33^{*}$ & \\
\hline obs & 96 & 96 & 96 & 96 & 96 & 96 & 96 & 96 & 96 & 96 & 96 & 96 \\
\hline Mean & 96.58 & 48.49 & 19.96 & 1.05 & 8.51 & -8.67 & 3.17 & -1.59 & 117.01 & 85.53 & 71.07 & 23.24 \\
\hline Std.Dev. & 114.39 & 11.27 & 2.25 & 0.33 & 0.30 & 5.78 & 3.78 & 1.15 & 10.21 & 1.35 & 88.46 & 10.72 \\
\hline Min & -9.48 & 37.03 & 17.01 & 0.68 & 8.03 & -23.79 & -1.87 & -3.93 & 98.76 & 84.11 & -10.36 & 10.78 \\
\hline $\operatorname{Max}$ & 511.00 & 72.29 & 23.65 & 1.73 & 9.06 & 3.92 & 12.66 & 0.72 & 138.29 & 92.53 & 590.74 & 56.66 \\
\hline
\end{tabular}

\begin{tabular}{|c|c|c|c|c|c|c|c|c|c|c|c|c|}
\hline Hungary & Spreads & ExtDebt & GGvDebt & int.paym. & Income & CA & Inflation & Fbalance & Trade0p & $\begin{array}{l}\text { Exch. } \\
\text { rate }\end{array}$ & $\begin{array}{r}\text { Short } \\
\text { i.r.spread }\end{array}$ & $\begin{array}{r}\text { EAequity } \\
\text { volat }\end{array}$ \\
\hline \multicolumn{13}{|l|}{ Spreads } \\
\hline ExtDebt & $0.33^{*}$ & & & & & & & & & & & \\
\hline GGvDebt & $0.30^{*}$ & $0.89^{*}$ & & & & & & & & & & \\
\hline int.paym. & -0.09 & $-0.43^{*}$ & $-0.68^{*}$ & & & & & & & & & \\
\hline Income & $0.33^{*}$ & $0.85^{*}$ & $0.97^{*}$ & $-0.75^{*}$ & & & & & & & & \\
\hline CA & $-0.30 *$ & -0.04 & -0.13 & 0.11 & -0.16 & & & & & & & \\
\hline Inflation & -0.03 & 0.00 & -0.13 & $0.49^{*}$ & -0.25 & 0.15 & & & & & & \\
\hline Fbalance & 0.09 & 0.23 & -0.14 & $0.54^{*}$ & -0.17 & 0.19 & $0.59 *$ & & & & & \\
\hline Trade0p & 0.11 & $0.77^{*}$ & $0.63^{*}$ & -0.02 & $0.53^{*}$ & 0.07 & $0.38^{*}$ & $0.38^{*}$ & & & & \\
\hline Exch. rate & $0.42^{*}$ & 0.24 & 0.19 & 0.04 & 0.09 & -0.07 & 0.04 & -0.05 & $0.34^{*}$ & & & \\
\hline $\begin{array}{l}\text { Short } \\
\text { i.r.spread }\end{array}$ & $0.44 *$ & $-0.53^{*}$ & $-0.53^{*}$ & $0.31^{*}$ & $-0.48^{*}$ & -0.07 & 0.22 & 0.09 & $-0.53^{*}$ & 0.10 & & \\
\hline EAequity volat & -0.05 & -0.10 & $-0.30^{*}$ & 0.01 & $-0.27^{*}$ & 0.08 & -0.05 & $0.27^{*}$ & -0.19 & -0.10 & 0.04 & \\
\hline obs & 96 & 96 & 96 & 96 & 96 & 96 & 96 & 96 & 96 & 96 & 96 & 96 \\
\hline Mean & 306.25 & 72.54 & 59.85 & 4.23 & 13.09 & -7.45 & 5.92 & -6.49 & 141.78 & 99.06 & 538.82 & 23.24 \\
\hline Std.Dev. & 76.64 & 17.43 & 4.71 & 0.32 & 0.19 & 1.54 & 2.10 & 2.18 & 14.12 & 3.57 & 202.49 & 10.72 \\
\hline Min & 152.28 & 52.30 & 52.08 & 3.96 & 12.70 & -10.56 & 2.26 & -9.67 & 118.95 & 90.94 & 256.16 & 10.78 \\
\hline Max & 521.00 & 119.30 & 65.81 & 5.30 & 13.36 & -1.32 & 10.75 & -2.44 & 174.42 & 108.86 & 1043.94 & 56.66 \\
\hline
\end{tabular}

\begin{tabular}{|c|c|c|c|c|c|c|c|c|c|c|c|c|}
\hline Poland & Spreads & ExtDebt & GGvDebt & int.paym. & Income & CA & Inflation & Fbalance & Trade0p & $\begin{array}{l}\text { Exch. } \\
\text { rate }\end{array}$ & $\begin{array}{r}\text { Short } \\
\text { i.r.spread }\end{array}$ & $\begin{array}{r}\text { EAequity } \\
\text { volat }\end{array}$ \\
\hline \multicolumn{13}{|l|}{ Spreads } \\
\hline ExtDebt & $-0.58^{*}$ & & & & & & & & & & & \\
\hline GGvDebt & $-0.77^{*}$ & $0.68^{*}$ & & & & & & & & & & \\
\hline int.paym. & $0.59^{*}$ & $-0.81^{*}$ & $-0.53^{*}$ & & & & & & & & & \\
\hline Income & $-0.59 *$ & $0.79 *$ & $0.59^{*}$ & $-0.96^{*}$ & & & & & & & & \\
\hline CA & 0.03 & $-0.36^{*}$ & 0.00 & $0.36^{*}$ & $-0.36^{*}$ & & & & & & & \\
\hline Inflation & $0.65^{*}$ & -0.12 & $-0.47^{*}$ & -0.07 & 0.02 & -0.24 & & & & & & \\
\hline Fbalance & -0.06 & $0.42^{*}$ & -0.05 & $-0.73^{*}$ & $0.735^{*}$ & $-0.46^{*}$ & $0.42^{*}$ & & & & & \\
\hline Trade0p & $-0.64^{*}$ & $0.78^{*}$ & $0.83^{*}$ & $-0.79^{*}$ & $0.85^{*}$ & -0.22 & -0.12 & $0.41^{*}$ & & & & \\
\hline Exch. rate & -0.13 & 0.11 & $0.40^{*}$ & $0.36^{*}$ & $-0.37^{*}$ & 0.18 & $-0.42^{*}$ & $-0.77^{*}$ & 0.02 & & & \\
\hline $\begin{array}{l}\text { Short } \\
\text { i.r.spread }\end{array}$ & $0.93^{*}$ & $-0.73^{*}$ & $-0.87^{*}$ & $0.70^{*}$ & $-0.74^{*}$ & 0.12 & $0.56^{*}$ & -0.19 & $-0.82^{*}$ & -0.11 & & \\
\hline EAequity volat & 0.10 & -0.00 & $-0.47^{*}$ & 0.05 & -0.17 & -0.11 & -0.08 & 0.10 & $-0.38^{*}$ & -0.08 & 0.19 & \\
\hline obs & 96 & 96 & 96 & 96 & 96 & 96 & 96 & 96 & 96 & 96 & 96 & 96 \\
\hline Mean & 230.96 & 43.78 & 44.09 & 2.79 & 8.73 & -3.33 & 2.73 & -4.28 & 73.55 & 95.16 & 391.90 & 23.24 \\
\hline Std.Dev. & 143.44 & 3.88 & 3.46 & 0.22 & 0.16 & 2.00 & 1.71 & 1.41 & 10.19 & 8.76 & 349.40 & 10.72 \\
\hline Min & 85.92 & 36.31 & 36.85 & 2.31 & 8.50 & -8.64 & 0.11 & -6.30 & 55.48 & 78.34 & 32.91 & 10.78 \\
\hline Max & 680.18 & 56.60 & 47.65 & 3.12 & 9.02 & 1.15 & 7.23 & -1.49 & 88.72 & 116.74 & 1418.56 & 56.66 \\
\hline
\end{tabular}

\begin{tabular}{|c|c|c|c|c|c|c|c|c|c|c|c|c|}
\hline Romania & Spreads & ExtDebt & GGvDebt & int.paym. & Income & CA & Inflation & Fbalance & Trade0p & $\begin{array}{r}\text { Exch. } \\
\text { rate }\end{array}$ & $\begin{array}{r}\text { Short } \\
\text { i.r.spread }\end{array}$ & $\begin{array}{r}\text { EAequity } \\
\text { volat }\end{array}$ \\
\hline \multicolumn{13}{|l|}{ Spreads } \\
\hline ExtDebt & 0.01 & & & & & & & & & & & \\
\hline GGvDebt & 0.36 & $-0.38^{*}$ & & & & & & & & & & \\
\hline int.paym. & $0.41^{*}$ & $-0.46^{*}$ & $0.98^{*}$ & & & & & & & & & \\
\hline Income & -0.23 & $0.78^{*}$ & $-0.72^{*}$ & $-0.78^{*}$ & & & & & & & & \\
\hline CA & $0.48^{*}$ & -0.31 & $0.73^{*}$ & $0.76^{*}$ & $-0.71^{*}$ & & & & & & & \\
\hline Inflation & 0.18 & 0.14 & $0.73^{*}$ & $0.65^{*}$ & -0.19 & $0.43^{*}$ & & & & & & \\
\hline Fbalance & 0.10 & $-0.64^{*}$ & 0.24 & 0.33 & $-0.71^{*}$ & $0.40^{*}$ & -0.14 & & & & & \\
\hline Trade0p & -0.24 & -0.26 & 0.05 & 0.05 & 0.06 & -0.29 & 0.09 & 0.07 & & & & \\
\hline Exch. rate & $0.54^{*}$ & $0.48^{*}$ & 0.32 & 0.28 & 0.15 & 0.26 & $0.64^{*}$ & -0.15 & -0.12 & & & \\
\hline $\begin{array}{l}\text { Short } \\
\text { i.r.spread }\end{array}$ & $0.53^{*}$ & $0.61^{*}$ & 0.07 & 0.07 & $0.40^{*}$ & 0.06 & 0.31 & -0.34 & -0.09 & $0.70^{*}$ & & \\
\hline EAequity volat & 0.20 & $0.77^{*}$ & -0.33 & -0.37 & $0.68^{*}$ & $\begin{array}{r}-0.19 \\
-0.19\end{array}$ & -0.01 & $-0.55^{*}$ & -0.25 & $0.44^{*}$ & $0.72^{*}$ & \\
\hline$o b s$ & 45 & 45 & 45 & 45 & 45 & 45 & 45 & 45 & 45 & 45 & 45 & 45 \\
\hline Mean & 326.19 & 41.94 & 13.98 & 0.93 & 8.36 & -11.47 & 7.02 & -1.52 & 79.03 & 189.93 & 513.03 & 19.97 \\
\hline Std.Dev. & 53.76 & 6.18 & 1.63 & 0.16 & 0.20 & 2.30 & 1.92 & 1.60 & 11.99 & 8.40 & 234.00 & 9.88 \\
\hline Min & 220.16 & 32.44 & 12.36 & 0.78 & 8.08 & -14.92 & 3.74 & -4.71 & 57.10 & 168.60 & 207.83 & 11.22 \\
\hline Max & 449.00 & 57.33 & 17.82 & 1.32 & 8.64 & -7.11 & 10.04 & 1.95 & 103.35 & 210.99 & 1309.69 & 56.66 \\
\hline
\end{tabular}




\begin{tabular}{|c|c|c|c|c|c|c|c|c|c|c|c|c|}
\hline Slovakia & Spreads & ExtDebt & GGvDebt & int.paym. & Income & CA & Inflation & Fbalance & Trade0p & $\begin{array}{r}\text { Exch. } \\
\text { rate }\end{array}$ & $\begin{array}{r}\text { Short } \\
\text { i.r.spread }\end{array}$ & $\begin{array}{r}\text { EAequity } \\
\text { volat }\end{array}$ \\
\hline Spreads & & & & & & & & & & & & \\
\hline ExtDebt & -0.00 & & & & & & & & & & & \\
\hline GGvDebt & $0.79 *$ & -0.23 & & & & & & & & & & \\
\hline int.paym. & $0.86^{*}$ & -0.18 & $0.95^{*}$ & & & & & & & & & \\
\hline Income & $-0.76^{*}$ & $0.28^{*}$ & $-0.97^{*}$ & $-0.9445^{*}$ & & & & & & & & \\
\hline CA & -0.06 & -0.06 & -0.07 & -0.0774 & 0.07 & & & & & & & \\
\hline Inflation & $0.41^{*}$ & $-0.41^{*}$ & $0.58^{*}$ & $0.4812^{*}$ & $-0.58^{*}$ & -0.03 & & & & & & \\
\hline Fbalance & $-0.80^{*}$ & 0.02 & $-0.74^{*}$ & $-0.8699 *$ & $0.76^{*}$ & 0.04 & -0.24 & & & & & \\
\hline Trade0p & $-0.48^{*}$ & $0.33^{*}$ & $-0.77^{*}$ & $-0.6837^{*}$ & $0.73^{*}$ & 0.03 & $-0.43^{*}$ & $0.35^{*}$ & & & & \\
\hline Exch. rate & $0.70^{*}$ & $-0.26^{*}$ & $0.93^{*}$ & $0.8782^{*}$ & $-0.96^{*}$ & -0.06 & $0.53^{*}$ & $-0.71^{*}$ & $-0.69 *$ & & & \\
\hline i.r.spread & $0.71^{*}$ & $-0.44 *$ & $0.87 *$ & $0.8755^{*}$ & $-0.91 *$ & -0.02 & $0.58^{*}$ & $-0.67^{*}$ & $-0.68^{*}$ & $0.90^{*}$ & & \\
\hline EAequity volat & $0.36^{*}$ & -0.21 & 0.22 & $0.40^{*}$ & -0.22 & 0.00 & 0.10 & $-0.39 *$ & $-0.30^{*}$ & 0.14 & $0.34^{*}$ & \\
\hline obs & 96 & 96 & 96 & 96 & 96 & 96 & 96 & 96 & 96 & 96 & 96 & 96 \\
\hline Mean & 98.72 & 52.04 & 38.59 & 2.43 & 7.66 & -7.16 & 4.93 & -4.27 & 159.76 & 91.05 & 199.21 & 23.24 \\
\hline Std.Dev. & 100.35 & 4.32 & 7.30 & 1.00 & 0.22 & 5.37 & 2.38 & 2.60 & 10.91 & 9.65 & 180.87 & 10.72 \\
\hline Min & -16.17 & 44.64 & 28.78 & 1.36 & 7.30 & -33.60 & 1.22 & -11.90 & 145.18 & 71.33 & -90.31 & 10.78 \\
\hline $\operatorname{Max}$ & 330.68 & 60.84 & 50.21 & 4.06 & 8.02 & 3.82 & 9.46 & -1.43 & 184.11 & 105.10 & 497.60 & 56.66 \\
\hline
\end{tabular}

Legend:

Spreads: denotes the spread between a new EU country long-term government bond yield and euro area average; GGvDebt denotes the government debt-to-GDP ratio, ExtDebt denotes the external debt-to-GDP ratio, int.paym. the interest payments-to-GDP ratio, FBalance the fiscal balance-to-GDP ratio, TradeOp the sum of exports and imports-to-GDP, CA the current account balance-toGDP, Income the logarithm of per capita income, Inflation, actual rates of inflation, Exch. rate the exchange rate as an index (Jan$00=100$ ), Short i.r.spread the short-term interest rates differentials over the three-month EURIBOR and EAeuity volat the euro area equity market volatility

\section{Unit Root tests}

Table A1.1: Results of the augmented Dickey-Fuller test that the series follow a unit-root process

\begin{tabular}{|l|l|l|l|l|l|l|l|l|}
\hline & BG & CZ & LV & LT & HU & PL & RO & SK \\
\hline spreads & -1.31 & -2.35 & 0.16 & -0.77 & -1.76 & -3.40 & -1.56 & -2.06 \\
\hline extdebt & 0.64 & -0.54 & 0.30 & 1.23 & 2.42 & 0.40 & 0.34 & -1.59 \\
\hline interestpay & -0.31 & -3.20 & -2.13 & -1.95 & -3.14 & 0.09 & -2.09 & -2.30 \\
\hline income & -0.66 & 1.28 & 0.08 & 0.04 & -1.47 & 0.47 & -0.83 & -0.18 \\
\hline ca & -1.88 & -2.47 & -1.56 & -2.15 & -3.14 & -2.48 & -1.67 & $4.88 \dagger$ \\
\hline infla & -2.60 & -2.61 & -2.47 & -1.46 & -3.41 & $-3.65 \dagger$ & -2.00 & -2.30 \\
\hline rollfiscal & -1.67 & -1.18 & -2.20 & -2.22 & -1.62 & -1.01 & -1.39 & -1.43 \\
\hline tradeop & 1.72 & -1.82 & -1.42 & -2.14 & -1.62 & -1.90 & $-5.08 \dagger$ & -2.02 \\
\hline fxindex & -2.00 & -1.38 & -2.16 & $-3.52 \dagger$ & -2.93 & -1.92 & -0.88 & 1.27 \\
\hline shortspreads & 0.71 & -1.82 & -2.18 & 0.06 & -1.92 & $-3.45 \dagger$ & -0.57 & -0.79 \\
\hline eaeqvol & -1.11 & -1.53 & -1.47 & -1.47 & -1.47 & -1.47 & 0.52 & -1.47 \\
\hline
\end{tabular}

Note: 4 lags were considered, $\dagger$ indicates that the null hypothesis that the series contains a unit root is rejected at $1 \%$.

Table A1.2: Results of the modified Dickey-Fuller $\mathrm{t}$ test for a unit root the optimum lag

\begin{tabular}{|l|l|l|l|l|l|l|l|l|}
\hline & BG & CZ & LV & LT & HU & PL & RO & SK \\
\hline spreads & -0.08 & -3.34 & -0.63 & -0.24 & -2.56 & -2.05 & -1.95 & -1.29 \\
\hline extdebt & -1.75 & -0.87 & -0.99 & -0.55 & -0.10 & -1.80 & -1.40 & -1.74 \\
\hline interestpay & -2.71 & -3.56 & -2.31 & -1.28 & -2.00 & -2.38 & -1.62 & -1.97 \\
\hline income & -1.29 & -1.64 & -0.68 & -0.75 & -0.16 & -0.33 & -4.23 & -1.34 \\
\hline ca & -2.48 & -3.52 & -1.63 & $-7.10 \dagger$ & -3.49 & -2.81 & -1.09 & -3.05 \\
\hline infla & $-4.17 \dagger$ & -3.11 & -4.18 & -2.65 & -2.54 & -1.76 & -2.89 & $-3.75 \dagger$ \\
\hline rollfiscal & $-4.24 \dagger$ & -2.14 & -2.30 & -1.86 & -1.71 & -1.36 & -2.77 & -2.26 \\
\hline tradeop & -0.74 & -2.11 & -0.36 & -1.73 & -1.41 & -1.19 & $-4.64 \dagger$ & -2.31 \\
\hline fxindex & -3.67 & -2.45 & -1.78 & -0.17 & -2.96 & -1.68 & -1.07 & -1.14 \\
\hline shortspreads & -1.08 & -2.34 & -3.04 & -0.34 & -2.22 & -1.22 & -1.76 & -1.64 \\
\hline eaeqvol & -0.29 & -2.22 & -2.12 & -2.12 & -2.12 & -2.12 & -2.69 & -2.12 \\
\hline
\end{tabular}

Note: DF-GLS tau test statistic is reported for the Ng-Perron optimum lag (maxlags=8; $\dagger$ indicates that the null hypothesis that the series contains a unit root is rejected at $1 \%$. 


\section{Appendix 2: Pooled Mean Group estimation results for individual variables}

General government debt-to-GDP ratio (GGvDebt)

Long-run

9.17***
\begin{tabular}{|l|r|r|r|r|r|r|r|r|}
\hline Short-run & \multicolumn{1}{|l|}{ BG } & \multicolumn{1}{l|}{ CZ } & \multicolumn{1}{l|}{ LV } & LT & HU & PL & \multicolumn{1}{l|}{ RO } & \multicolumn{1}{l|}{ SK } \\
\hline ec & 0.15 & 0.02 & -0.03 & -0.06 & $-0.12^{* *}$ & $-0.04^{* *}$ & -0.15 & $-0.07^{* *}$ \\
\hline D.GGvDebt & 14.70 & $-22.10^{* *}$ & $70.84^{* *}$ & $223.16^{* * *}$ & -9.05 & -8.85 & -3.70 & $25.87^{* *}$ \\
\hline cons & $38.30^{* *}$ & 4.74 & 2.17 & 9.93 & -25.60 & $-9.40^{*}$ & 32.23 & -15.89 \\
\hline
\end{tabular}

\section{External debt-to-GDP ratio (ExtDebt)}

\section{Long-run}

$24.06^{* *}$

\begin{tabular}{|l|r|r|r|r|r|r|r|r|}
\hline Short-run & \multicolumn{1}{l|}{ BG } & \multicolumn{1}{l}{ CZ } & \multicolumn{1}{l}{ LV } & LT & HU & \multicolumn{1}{l|}{ PL } & \multicolumn{1}{l|}{ RO } & \multicolumn{1}{l|}{ SK } \\
\hline ec & $-0.03^{* *}$ & -0.02 & $-0.02^{*}$ & $-0.04^{* *}$ & -0.00 & $-0.02^{* *}$ & $-0.07^{*}$ & $-0.04^{* *}$ \\
\hline D.ExtDebt & -1.55 & 2.69 & -0.59 & -0.03 & 3.09 & $6.48^{*}$ & $-4.16^{*}$ & $-2.97^{* *}$ \\
\hline _cons & $-64.19^{* * *}$ & -23.24 & $-37.64^{* * *}$ & $-43.92^{* * *}$ & -7.75 & $-27.97^{* *}$ & $-47.29^{* *}$ & $-49.86^{* *}$ \\
\hline
\end{tabular}

\section{Interest payments on public debt-to-GDP ratio (int.paym.)}

\section{Long-run}

\subsection{3**}

\begin{tabular}{|l|r|r|r|r|r|r|r|r|}
\hline Short-run & \multicolumn{1}{|l|}{ BG } & \multicolumn{1}{l|}{ CZ } & LV & LT & HU & PL & \multicolumn{1}{l|}{ RO } & \multicolumn{1}{l|}{ SK } \\
\hline ec & $-0.04^{* *}$ & $-0.09^{* *}$ & -0.02 & -0.03 & -0.04 & $-0.03^{* *}$ & 0.00 & $-0.01^{*}$ \\
\hline D. int.paym. & 313.28 & $-615.43^{* * *}$ & $1542.77^{* * *}$ & 569.98 & -12.52 & 387.15 & 255.64 & -25.19 \\
\hline _cons & $43.75^{* *}$ & $50.61^{*}$ & $19.63^{*}$ & $24.40^{* *}$ & $101.74^{*}$ & $54.68^{* *}$ & 1.37 & 6.40 \\
\hline
\end{tabular}

Fiscal Balance-to-GDP ratio (FBalance)

\section{Long-run}

7.79

\begin{tabular}{|l|r|r|r|r|r|r|r|r|}
\hline Short-run & \multicolumn{1}{|l|}{ BG } & \multicolumn{1}{l|}{ CZ } & \multicolumn{1}{l|}{ LV } & LT & HU & PL & \multicolumn{1}{l|}{ RO } & \multicolumn{1}{l|}{ SK } \\
\hline ec & -0.07 & -0.03 & 0.02 & -0.04 & $-0.10^{* *}$ & -0.02 & -0.10 & $-0.04^{* *}$ \\
\hline D. FBalance & $23.02^{* * *}$ & $14.52^{* * *}$ & $38.24^{* *}$ & 24.94 & 14.66 & $47.23^{*}$ & 8.48 & 13.00 \\
\hline cons & 3.95 & 1.19 & -0.35 & 4.97 & $38.45^{* *}$ & 1.33 & 37.88 & 2.57 \\
\hline
\end{tabular}

Trade openness (TradeOp)

Long-run

$-2.59$

\begin{tabular}{|l|r|r|r|r|r|r|r|r|}
\hline Short-run & \multicolumn{1}{|l|}{ BG } & \multicolumn{1}{l|}{ CZ } & \multicolumn{1}{l|}{ LV } & \multicolumn{1}{l|}{ LT } & HU & \multicolumn{1}{l|}{ PL } & \multicolumn{1}{l|}{ RO } & \multicolumn{1}{l|}{ SK } \\
\hline ec & -0.09 & $-0.04^{*}$ & 0.02 & -0.05 & -0.07 & $-0.04^{*}$ & $-0.18^{* *}$ & $-0.05^{* *}$ \\
\hline D.Trade0p & $-2.96^{* * *}$ & 0.56 & $-2.98^{*}$ & $-6.13^{* * *}$ & $2.01^{*}$ & 1.37 & 0.47 & -0.30 \\
\hline _cons & 43.96 & 15.77 & -4.51 & 20.28 & 46.97 & 13.21 & $100.19^{* *}$ & 25.64 \\
\hline
\end{tabular}

\section{Current Account balance-to-GDP ratio (CA)}

\section{Long-run}

$-28.85^{*}$

\begin{tabular}{|l|r|r|r|r|r|r|r|r|}
\hline Short-run & BG & CZ & LV & LT & HU & PL & RO & SK \\
\hline ec & -0.02 & 0.01 & -0.00 & -0.00 & $-0.11^{* *}$ & $-0.05^{* * *}$ & -0.03 & -0.02 \\
\hline D.CA & 0.82 & $-0.57^{*}$ & 1.22 & 0.31 & $7.85^{*}$ & 2.05 & 2.53 & -0.00 \\
\hline ccons & -6.22 & 1.73 & 2.50 & 0.55 & 11.18 & 2.91 & 2.79 & -4.59 \\
\hline
\end{tabular}

\section{Ln of per capita income (Income)}

Long-run

2428.90

\begin{tabular}{|l|r|r|r|r|r|r|r|r|}
\hline Short-run & \multicolumn{1}{|l|}{ BG } & \multicolumn{1}{l|}{ CZ } & LV & LT & HU & PL & \multicolumn{1}{l|}{ RO } & \multicolumn{1}{l|}{ SK } \\
\hline ec & -0.02 & -0.00 & -0.01 & -0.02 & -0.01 & -0.01 & -0.01 & -0.01 \\
\hline D.Income & -58.83 & 122.26 & -40.40 & 33.19 & 244.39 & -36.20 & 0.97 & -196.07 \\
\hline _cons & $-384.60^{* * *}$ & -77.07 & $-164.85^{* * *}$ & $-368.50^{* * *}$ & -332.29 & -244.43 & -164.43 & $-129.09^{* *}$ \\
\hline
\end{tabular}


Inflation rate (Inflation)

Long-run

$70.05^{* * *}$
\begin{tabular}{|l|r|r|r|r|r|r|r|r|}
\hline Short-run & \multicolumn{1}{|l|}{ BG } & \multicolumn{1}{l|}{ CZ } & LV & LT & HU & PL & \multicolumn{1}{l|}{ RO } & \multicolumn{1}{l|}{ SK } \\
\hline ec & $-0.03^{*}$ & -0.01 & -0.02 & -0.03 & 0.02 & $-0.07^{* * *}$ & $-0.07^{*}$ & $-0.03^{*}$ \\
\hline D.Inflation & $-10.61^{* *}$ & 4.56 & $-16.91^{* * *}$ & -9.18 & 4.57 & 7.50 & -5.74 & 4.70 \\
\hline cons & -10.56 & -1.21 & 0.05 & 2.62 & 5.710 & -0.62 & -8.91 & $-9.16^{* *}$ \\
\hline
\end{tabular}

Exchange rate (Exch.Rate)

Long-run

-8.95***
\begin{tabular}{|l|r|r|r|r|r|r|r|r|}
\hline Short-run & \multicolumn{1}{|l|}{ BG } & \multicolumn{1}{l|}{ CZ } & LV & LT & HU & PL & \multicolumn{1}{l|}{ RO } & \multicolumn{1}{l|}{ SK } \\
\hline ec & $-0.08^{*}$ & -0.01 & $0.15^{* * *}$ & $0.09^{* *}$ & 0.01 & -0.02 & -0.04 & $-0.03^{* * *}$ \\
\hline D.Exch.rate & 1.85 & 1.85 & 4.90 & 10.89 & $13.57^{* * *}$ & $2.76^{* *}$ & $2.71^{* *}$ & $9.52^{* * *}$ \\
\hline cons & 88.05 & 5.74 & $-163.18^{* * *}$ & $-69.26^{*}$ & -12.82 & 20.62 & 88.82 & $28.69^{* * *}$ \\
\hline
\end{tabular}

Short-term interest rate differentials related to the euro area (Short i.r.spread)

Long-run

Euro area equity volatility (EAequity volat)

Long-run

8.68***
\begin{tabular}{|l|r|r|r|r|r|r|r|r|r|}
\hline Short-run & \multicolumn{1}{|c|}{ BG } & CZ & LV & LT & HU & PL & \multicolumn{1}{l|}{ RO } & SK \\
\hline ec & $-0.30^{* * *}$ & -0.01 & 0.00 & -0.01 & -0.03 & -0.02 & $-0.12^{* *}$ & -0.02 \\
\hline $\begin{array}{l}\text { D. EAequity } \\
\text { volat }\end{array}$ & $-3.09^{* * *}$ & 0.14 & -0.34 & -0.89 & $3.36^{* *}$ & $1.29^{* *}$ & -0.80 & $0.69^{*}$ \\
\hline _cons & $-26.62^{* * *}$ & -2.72 & 5.06 & 5.70 & 6.54 & -3.51 & 20.89 & $-4.97^{*}$ \\
\hline
\end{tabular}

Note: D. denotes the first difference of variables. 
Appendix 3a: Actual and estimated long-term spreads in first differences based on the main model
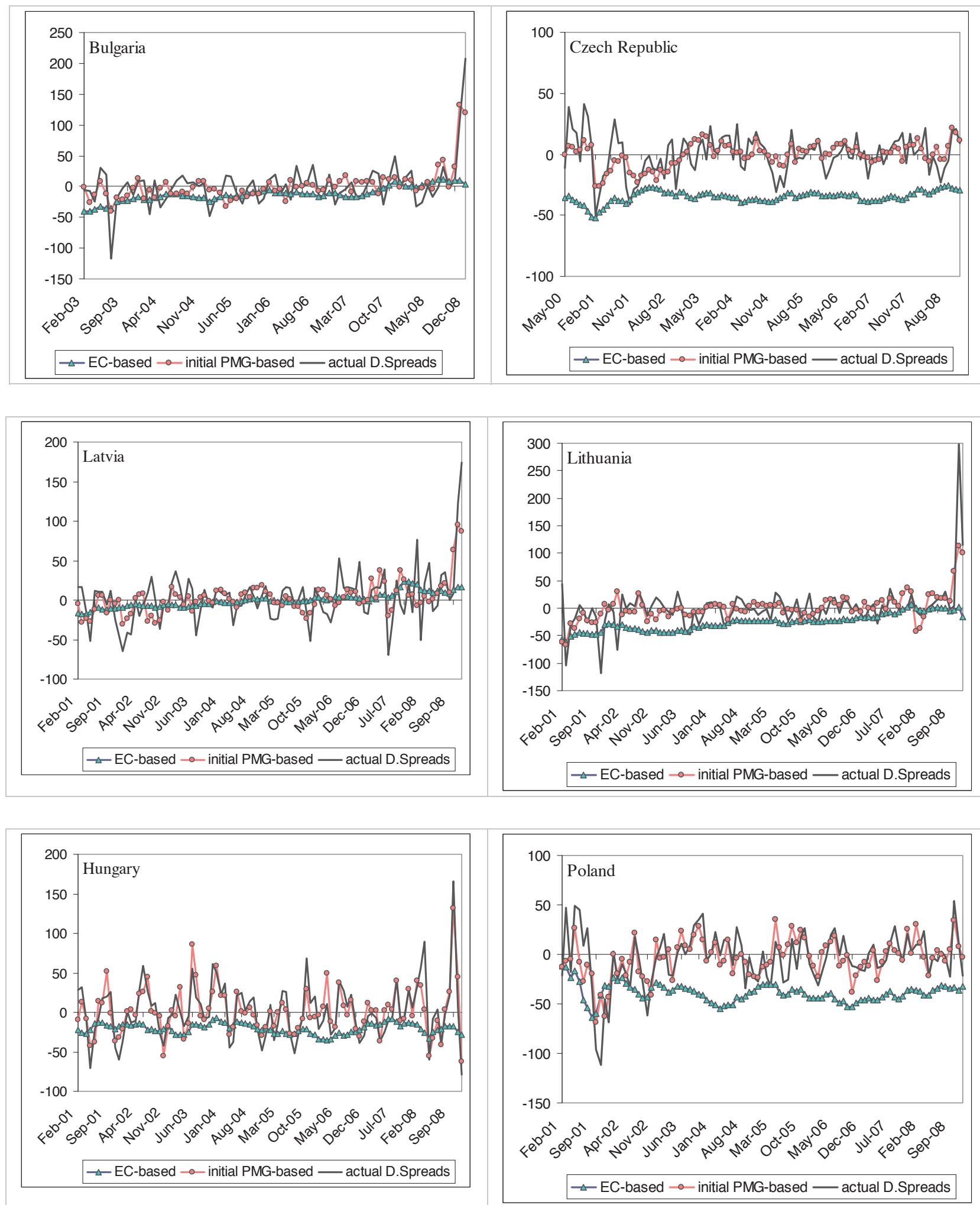

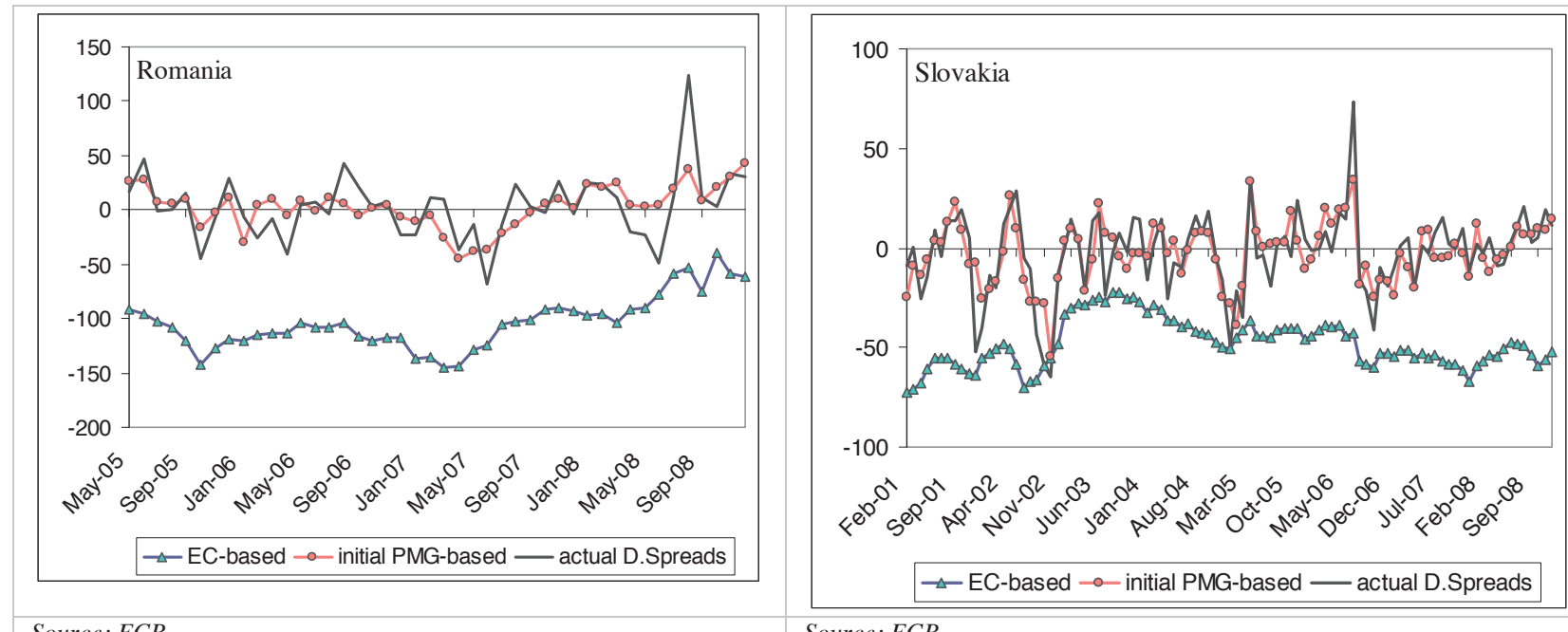

Source: $E C B$.

Source: $E C B$

Notes: EC-based is the long-run equilibrium component of estimated spreads (in first difference), initial PMG-based are the estimated first differenced spreads based on the whole model (coefficients reported in Tables 1a-b) and the actual D.Spreads denote the observed series of spreads (also in first difference). Last observation refers to December 2008.

\section{Appendix 3b: Actual and estimated long-term spreads in first differences based on the two groups specifications}
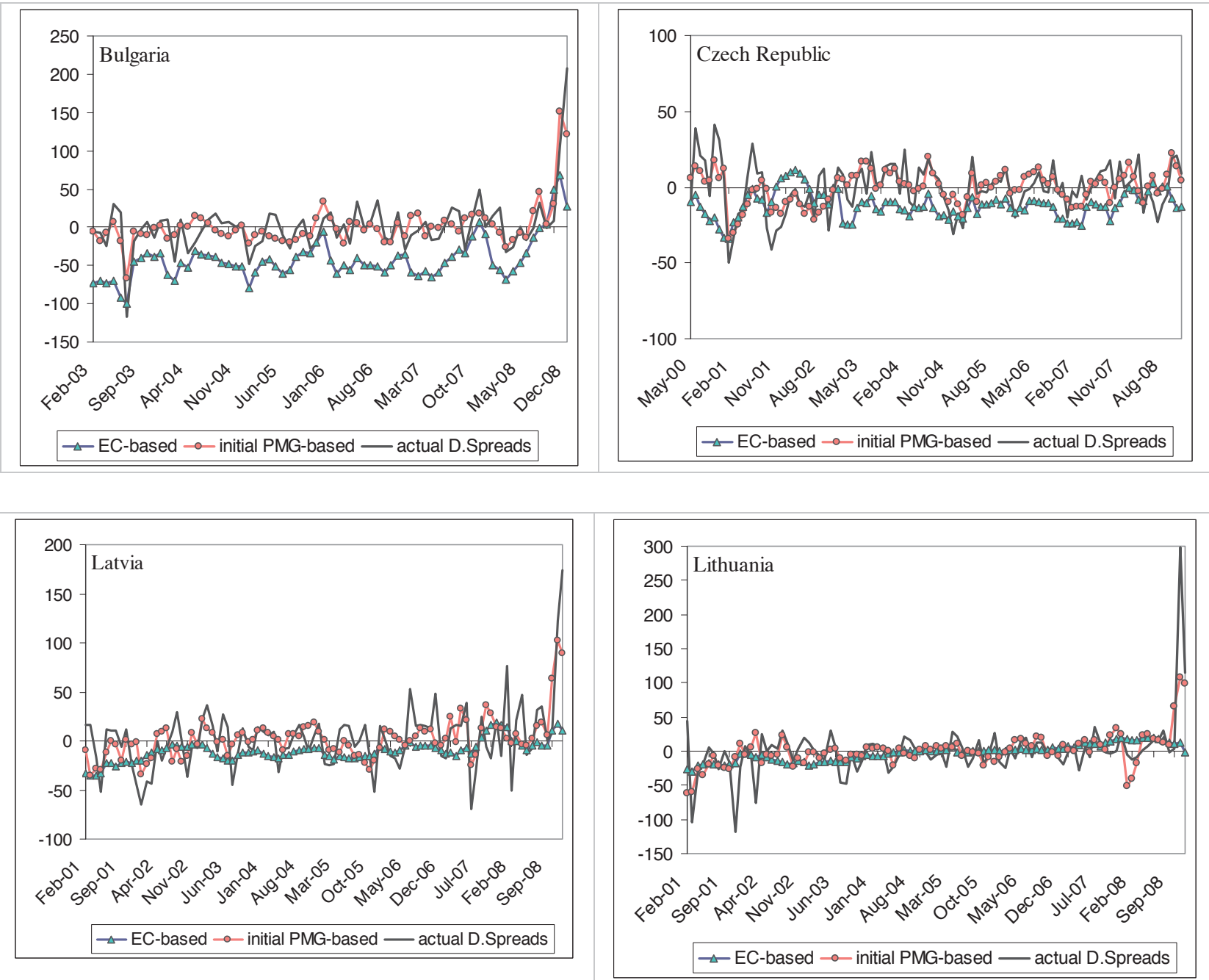

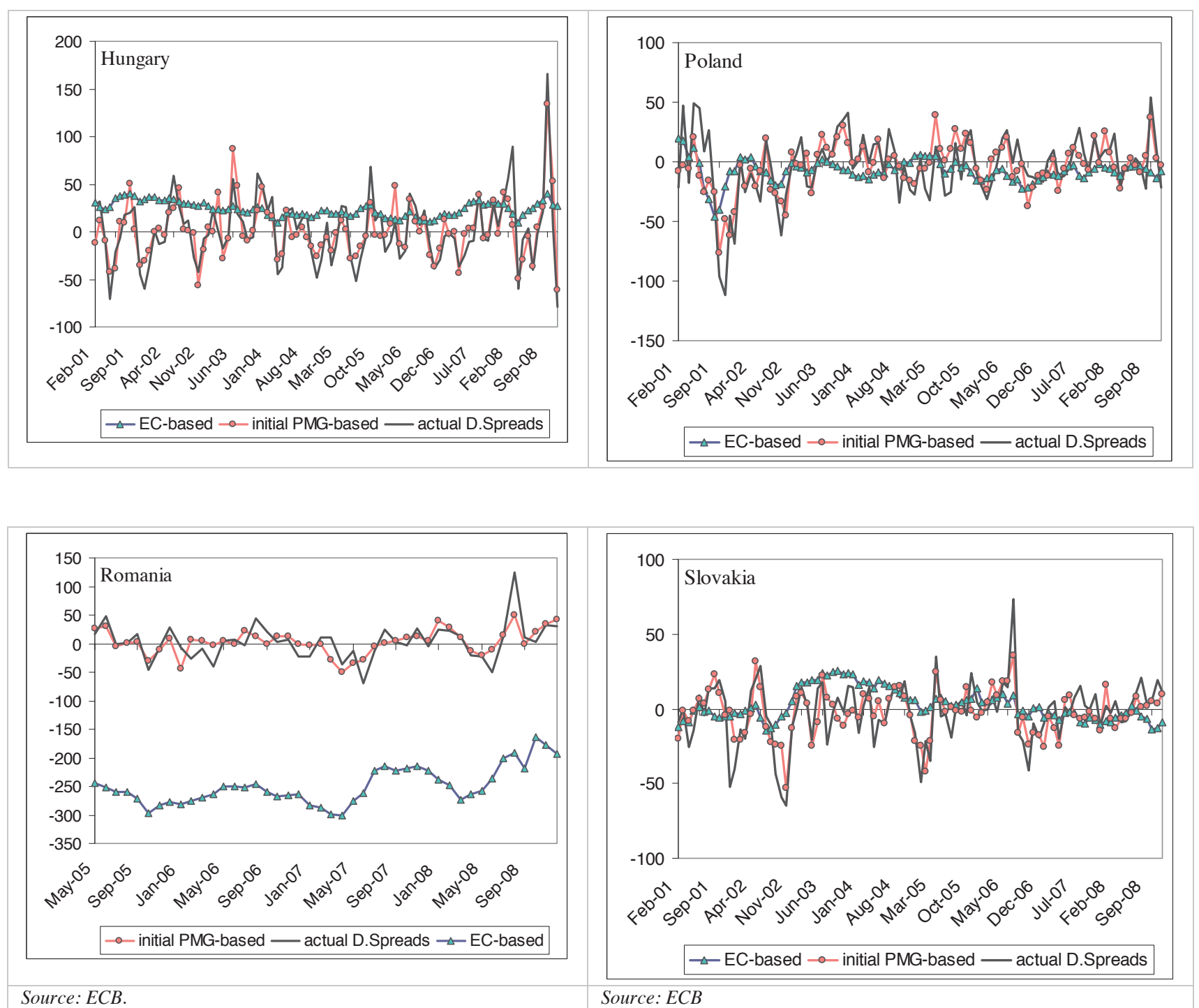

Notes: EC-based is the long-run equilibrium component of estimated spreads (in first difference), initial PMG-based are the estimated first differenced spreads based on the two groups specifications as in Figures 3 and 4 and the actual D.Spreads denote the observed series of spreads (also in first difference). Last observation refers to December 2008. 


\section{European Central Bank Working Paper Series}

For a complete list of Working Papers published by the ECB, please visit the ECB's website (http://www.ecb.europa.eu).

1059 "Forecasting the world economy in the short-term" by A. Jakaitiene and S. Dées, June 2009.

1060 "What explains global exchange rate movements during the financial crisis?" by M. Fratzscher, June 2009.

I06I "The distribution of households consumption-expenditure budget shares” by M. Barigozzi, L. Alessi, M. Capasso and G. Fagiolo, June 2009.

1062 "External shocks and international inflation linkages: a global VAR analysis" by A. Galesi and M. J. Lombardi, June 2009.

1063 “Does private equity investment spur innovation? Evidence from Europe” by A. Popov and P. Roosenboom, June 2009.

1064 "Does it pay to have the euro? Italy's politics and financial markets under the lira and the euro" by M. Fratzscher and L. Stracca, June 2009.

1065 "Monetary policy and inflationary shocks under imperfect credibility” by M. Darracq Pariès and S. Moyen, June 2009.

1066 "Universal banks and corporate control: evidence from the global syndicated loan market" by M. A. Ferreira and P. Matos, July 2009.

1067 "The dynamic effects of shocks to wages and prices in the United States and the euro area" by R. Duarte and C. R. Marques, July 2009.

1068 "Asset price misalignments and the role of money and credit” by D. Gerdesmeier, H.-E. Reimers and B. Roffia, July 2009.

1069 “Housing finance and monetary policy” by A. Calza, T. Monacelli and L. Stracca, July 2009.

1070 “Monetary policy committees: meetings and outcomes” by J. M. Berk and B. K. Bierut, July 2009.

I07I "Booms and busts in housing markets: determinants and implications" by L. Agnello and L. Schuknecht, July 2009.

1072 "How important are common factors in driving non-fuel commodity prices? A dynamic factor analysis" by I.Vansteenkiste, July 2009.

1073 “Can non-linear real shocks explain the persistence of PPP exchange rate disequilibria?" by T. Peltonen, M. Sager and A. Popescu, July 2009.

1074 "Wages are flexible, aren't they? Evidence from monthly micro wage data” by P. Lünnemann and L. Wintr, July 2009.

1075 “Bank risk and monetary policy” by Y. Altunbas, L. Gambacorta and D. Marqués-lbáñez, July 2009.

1076 "Optimal monetary policy in a New Keynesian model with habits in consumption” by C. Leith, I. Moldovan and R. Rossi, July 2009.

1077 "The reception of public signals in financial markets - what if central bank communication becomes stale?" by M. Ehrmann and D. Sondermann, August 2009. 
1078 "On the real effects of private equity investment: evidence from new business creation" by A. Popov and P. Roosenboom, August 2009.

1079 "EMU and European government bond market integration” by P. Abad and H. Chuliá, and M. Gómez-Puig, August 2009.

1080 "Productivity and job flows: heterogeneity of new hires and continuing jobs in the business cycle" by J. Kilponen and J. Vanhala, August 2009.

108I “Liquidity premia in German government bonds" by J. W. Ejsing and J. Sihvonen, August 2009.

1082 “Disagreement among forecasters in G7 countries” by J. Dovern, U. Fritsche and J. Slacalek, August 2009.

1083 "Evaluating microfoundations for aggregate price rigidities: evidence from matched firm-level data on product prices and unit labor cost” by M. Carlsson and O. Nordström Skans, August 2009.

1084 "How are firms' wages and prices linked: survey evidence in Europe" by M. Druant, S. Fabiani, G. Kezdi, A. Lamo, F. Martins and R. Sabbatini, August 2009.

1085 "An empirical study on the decoupling movements between corporate bond and CDS spreads" by I. Alexopoulou, M. Andersson and O. M. Georgescu, August 2009.

1086 "Euro area money demand: empirical evidence on the role of equity and labour markets" by G. J. de Bondt, September 2009.

1087 "Modelling global trade flows: results from a GVAR model” by M. Bussière, A. Chudik and G. Sestieri, September 2009.

1088 "Inflation perceptions and expectations in the euro area: the role of news" by C. Badarinza and M. Buchmann, September 2009.

1089 "The effects of monetary policy on unemployment dynamics under model uncertainty: evidence from the US and the euro area" by C. Altavilla and M. Ciccarelli, September 2009.

1090 “New Keynesian versus old Keynesian government spending multipliers” by J. F. Cogan, T. Cwik, J. B. Taylor and V. Wieland, September 2009.

109I "Money talks" by M. Hoerova, C. Monnet and T. Temzelides, September 2009.

1092 "Inflation and output volatility under asymmetric incomplete information" by G. Carboni and M. Ellison, September 2009.

1093 "Determinants of government bond spreads in new EU countries" by I. Alexopoulou, I. Bunda and A. Ferrando, September 2009. 
